\title{
Diastema interincisivos centrais superiores: quando e como intervir?
}

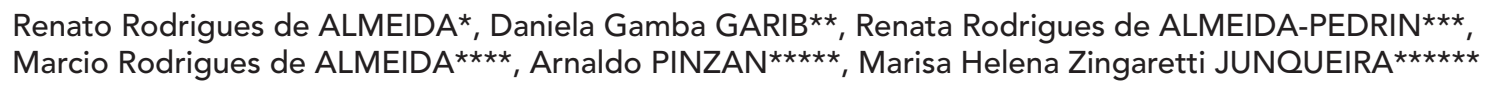

\section{Resumo}

Contemporaneamente, os diastemas interincisivos centrais superiores são vistos como um fator antiestético sendo altamente prejudicial do ponto de vista social. O diagnóstico diferencial dessa anomalia da oclusão deve ser realizado o mais cedo possível, não só para orientar o paciente e seus pais bem como para encetar o tratamento procurando devolver ao paciente uma estética agradável e o bem estar social. Na realidade o diastema mediano constitui um aspecto de normalidade durante a infância e, com o desenvolvimento da oclusão, há um fechamento fisiológico significativo. A sua persistência depende da etiologia que é multifatorial e geralmente está relacionada a: discrepância dente-osso positiva, microdontia, agenesias dos incisivos laterais superiores, hábitos principalmente de sucção, dentes supranumerários irrompidos ou ainda intra-ósseo, hereditariedade, freio labial hipertrófico e outros. O objetivo principal desse trabalho é o de nortear o leitor com relação à época (quando) e como intervir para o cerramento desse espaço.

Palavras-chave: Diastema. Freio labial. Etiologia. Tratamento ortodôntico.

\section{INTRODUÇÃO}

Foco de interesse de odontopediatras, ortodontistas, clínicos gerais e periodontistas, o diastema entre os incisivos centrais superiores remete a inúmeras dúvidas quanto à sua abordagem clínica. A presença de espaço interdentário na região mediana do arco superior desfavorece a beleza do sorriso e a harmonia do conjunto dentofacial (Fig. 1A-C). Sabe-se que os aspectos concernentes à auto-estima, além da atratividade facial, podem contribuir negativamente no bem-estar e nas relações sociais do ser humano ${ }^{1}$. Um interessante estudo europeu evidenciou que pacientes portadores de um amplo diastema mediano transpa-

* Professor Doutor da Disciplina de Ortodontia da Faculdade de Odontologia de Bauru-USP; Professor Responsável pela Disciplina de Ortodontia em nível de graduação e professor da especialização de Ortodontia da Faculdade de Odontologia de Lins - UNIMEP e Professor Associado da Universidade Cidade de São Paulo- UNICID.

** Mestre e Doutora em Ortodontia pela Faculdade de Odontologia de Bauru - USP; Professora da disciplina de Ortodontia da Universidade Paulista - Campus Bauru; Coordenadora do curso de especialização em Ortodontia da Prev Odonto Centro de Estudos - Rio de Janeiro.

*** Mestre e Doutora em Ortodontia pela Faculdade de Odontologia de Bauru-USP e Professora da Disciplina de Ortodontia (Graduação e Especialização) da Faculdade de Odontologia de Lins - UNIMEP.

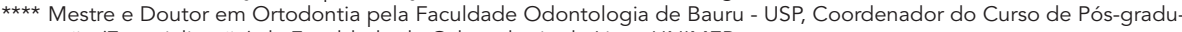
ação (Especialização) da Faculdade de Odontologia de Lins - UNIMEP

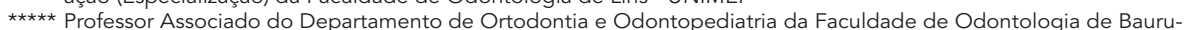
USP; Professor Responsável pela Disciplina de Ortodontia da Universidade do Sagrado Coração de Jesus-USC e Professor Associado da Universidade Cidade de São Paulo UNICID-SP.

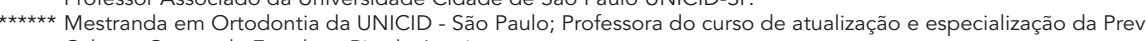
Odonto Centro de Estudos - Rio de Janeiro. 
reciam pessoas de menor inteligência e menor sucesso social ${ }^{13}$. Reconhecendo-se a importância da estética facial na sociedade contemporânea, diante do diastema interincisivos centrais superiores, o profissional freqüentemente anseia por cerrá-lo. No entanto, antes de qualquer conduta, deve-se avaliar a necessidade e a época mais oportuna para realizar tal procedimento, com base em conhecimentos sólidos sobre o desenvolvimento da oclusão e sobre a etiologia das más oclusões, que permitam distinguir o diastema fisiológico daquele que denota anormalidade e realmente requer tratamento.

$\mathrm{Na}$ realidade, o diastema mediano constitui um aspecto de normalidade durante a infância. $\mathrm{Na}$ dentadura decídua, aproximadamente $77 \%$ das crianças apresentam um arco dentário com espaçamentos ${ }^{24}$, denominado de arco tipo I por Baume (Fig. 2A-C). Os diastemas entre os diminutos dentes decíduos não comprometem a estética da criança, pelo contrário, atribui uma certa graça ao seu sorriso. Ademais, a presença de diastemas generalizados na dentadura decídua melhora o prognóstico para o alinhamento espontâneo dos incisivos permanentes duran- te a dentadura mista. Um estudo longitudinal em brasileiros, descendentes de mediterrâneos, mostrou que os incisivos permanentes irrompem alinhados em $50 \%$ das crianças que apresentam arco tipo I de Baume, e em apenas 22\% das crianças sem diastemas na dentadura decídua, ou com arco tipo II de Baume ${ }^{24}$ (Fig. 3AC). Esses números expressam que a presença de diastemas entre os dentes decíduos não garante que haverá espaço suficiente para acomodar os incisivos permanentes, marcantemente maiores que seus sucessores decíduos. No entanto, as crianças com arco tipo I apresentam o dobro de chances de alinhamento dos incisivos permanentes que as crianças com arco tipo II.

$\mathrm{Na}$ dentadura mista, os diastemas continuam a figurar como característica fisiológica, principalmente o diastema entre os incisivos centrais superiores permanentes. Os germes desses dentes mantém-se separados no interior da maxila, respeitando uma estrutura anatômica entre eles interposta, a sutura intermaxilar. E irrompem na boca mantendo tal separação (Fig. 4A-C). Esse diastema mediano mostra-se presente quase na totalidade das crianças no primeiro período tran-

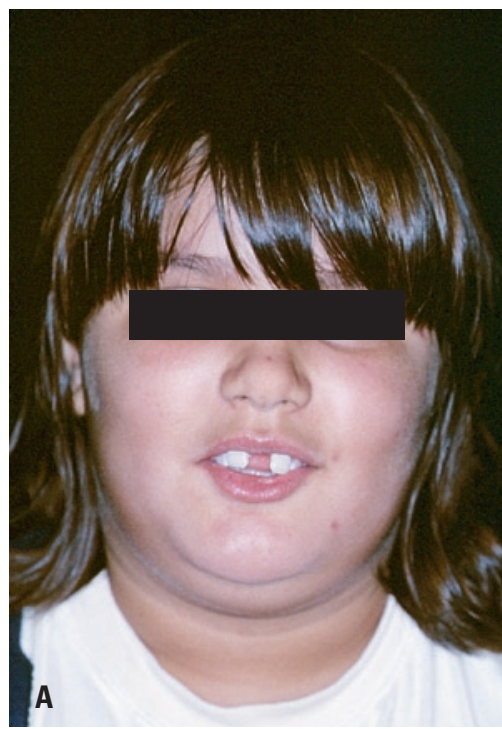

FIGURA 1 A, B - Diastema interincisivos centrais superiores comprometendo a estética do sorriso.

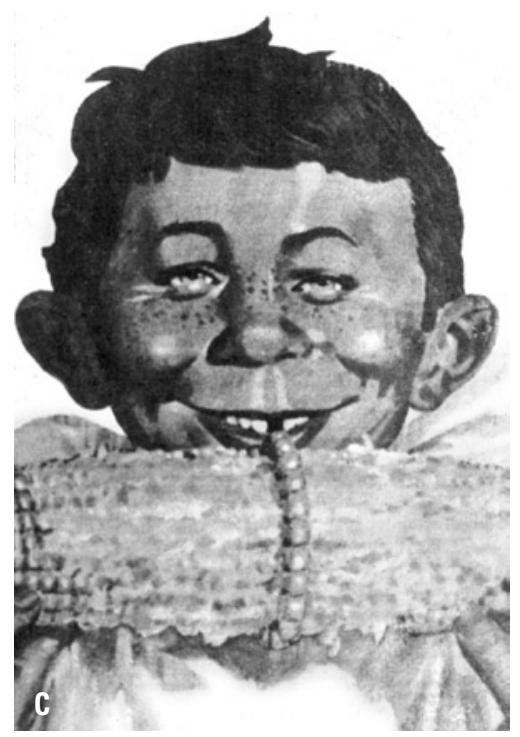

FIGURA (1C) - Interferência na mastigação (desvantagem do diastema). Fonte: Revista MAD. 

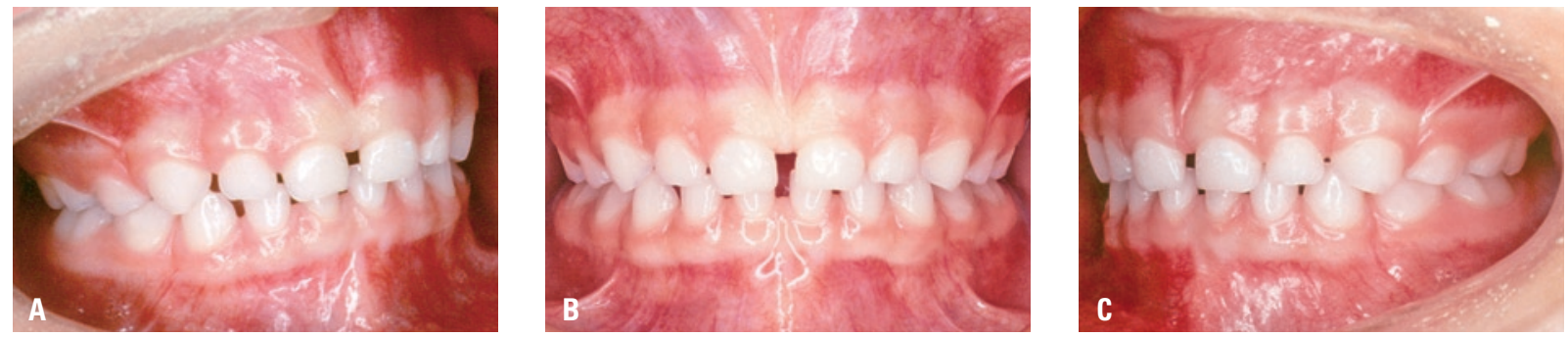

FIGURA 2A, B, C - Arco tipo I de Baume - espaçamentos fisiológicos.
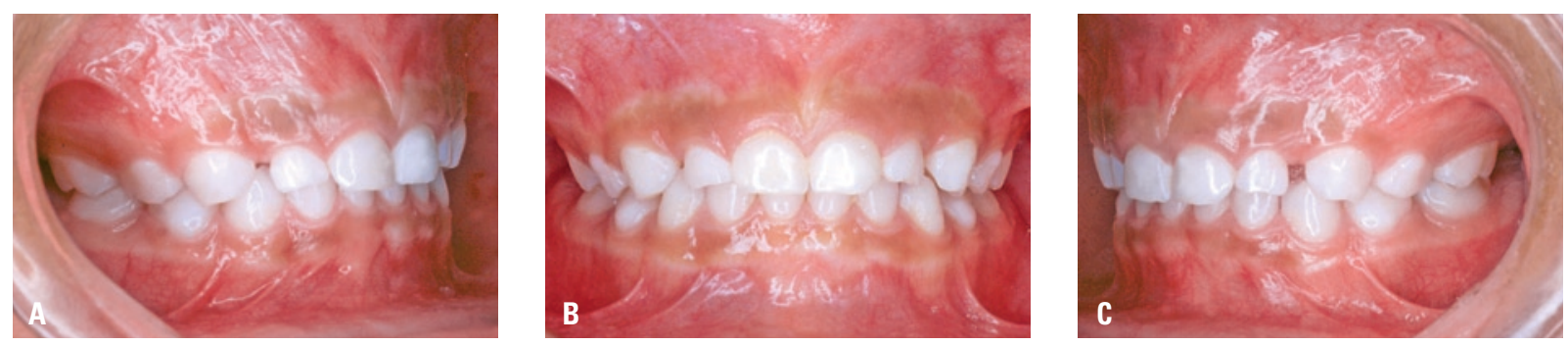

FIGURA 3A, B, C - Arco tipo Il de Baume - sem diastemas, apenas espaços primatas.

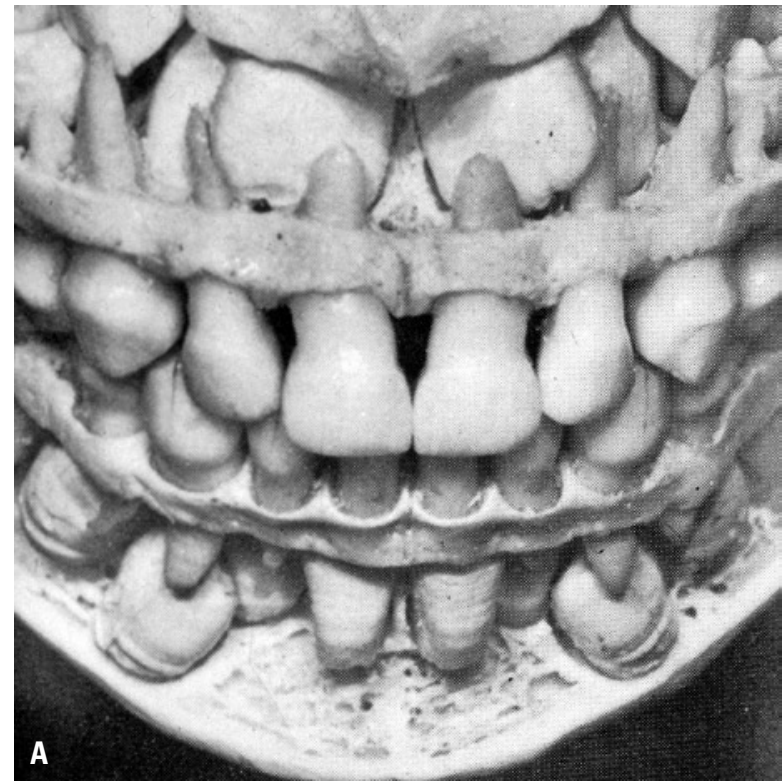

FIGURA 4 A - Germes dos incisivos centrais superiores permanentes com diastema. Fonte: Van der Linden.

sitório da dentadura mista e constitui uma das características da clássica fase do "patinho feio" de Broadbent ${ }^{6}$. Mas em condições de normalidade, ele diminui com a irrupção dos incisivos laterais superiores e fecha-se espontaneamente, ao final da
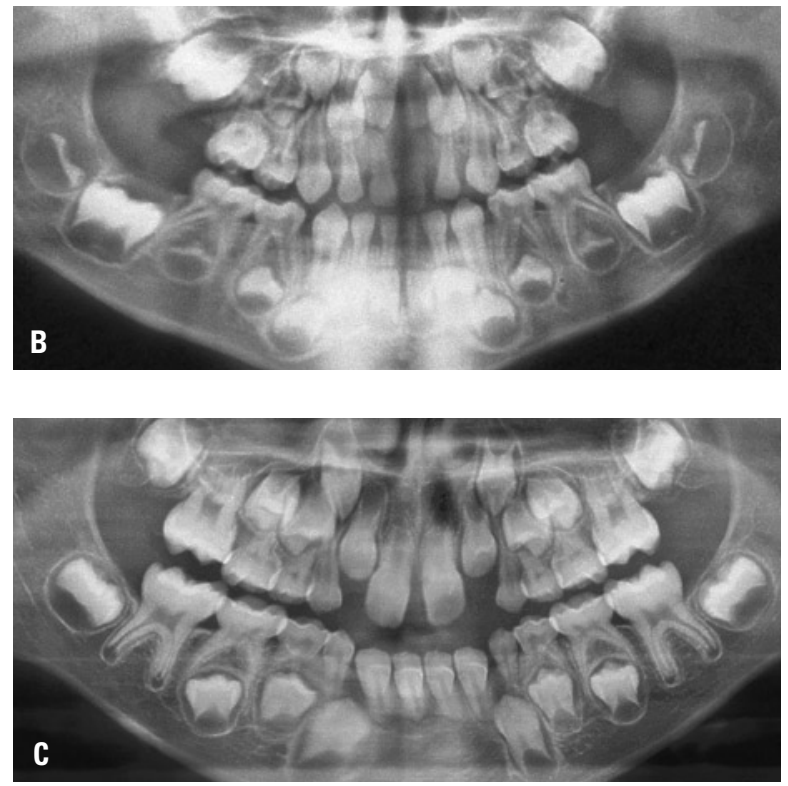

FIGURA 4 B, C - Radiografias panorâmicas evidenciando o diastema intra-ósseo e incisivos irrompidos com diastema presente.

dentadura mista, com a irrupção dos caninos superiores (Fig. 5A-J). Segundo Taylor ${ }^{30}$, o diastema mediano no arco superior mostra-se presente em 97\% das crianças durante a irrupção dos incisivos centrais superiores permanentes. Com a irrupção 
dos incisivos laterais superiores permanentes, esta porcentagem diminui para $46 \%$ a $48 \%$ e após a irrupção dos caninos superiores permanentes, a prevalência cai para $7 \%$. O estudo longitudinal de Sanin; Sekiguchi; Savara ${ }^{25}$ correlacionou o tamanho do diastema (em milímetros) com a probabilidade de fechamento espontâneo destes e demonstrou que para diastemas de até $1,85 \mathrm{~mm}$ a possibilidade de autocorreção é de $50 \%$; esta probabilidade de fechamento fisiológico diminuiu quanto maior for o diastema. Portanto a natureza encube-se de fechar a maioria dos diastemas interincisivos centrais superiores, dispensando qualquer interferência do odontólogo. Diante do diastema mediano na dentadura mista, a atitude mais sensata do clínico resume-se no acompanhamento longitudinal do desenvolvimento da oclusão, pois o fechamento precoce desse espaço, antes da irrupção dos caninos permanentes su- periores pode verticalizar os incisivos superiores diminuindo gradativamente os espaços para a irrupção dos caninos, agravando sobremaneira o desenvolvimento normal da oclusão. Em regra, nada deve ser realizado antes da irrupção dos caninos superiores permanentes.

Mas toda regra apresenta exceções, e o diastema interincisivos centrais, com ampla dimensão, pode ser fechado precocemente, ainda na dentadura mista, em dois casos:

1) quando não existe espaço suficiente entre os incisivos centrais permanentes e os caninos decíduos para a irrupção dos incisivos laterais permanentes (Fig. 6A-F). Nesta situação, o movimento mesial recíproco dos incisivos centrais proporciona espaço distal, favorecendo o alinhamento dos incisivos laterais no arco dentário;

2) na presença de hábitos persistentes de sucção, quando o dedo ou a chupeta são acomodados
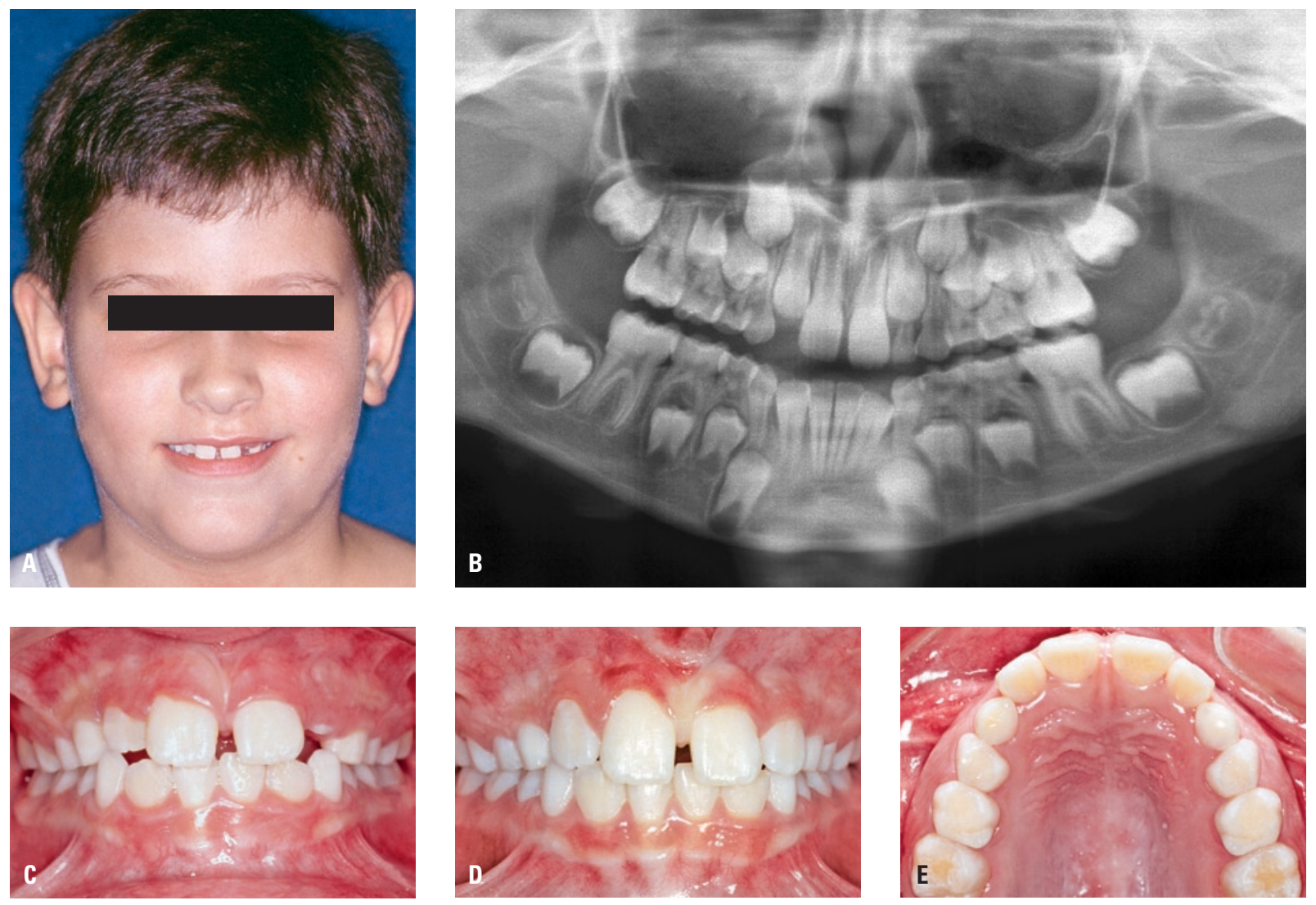

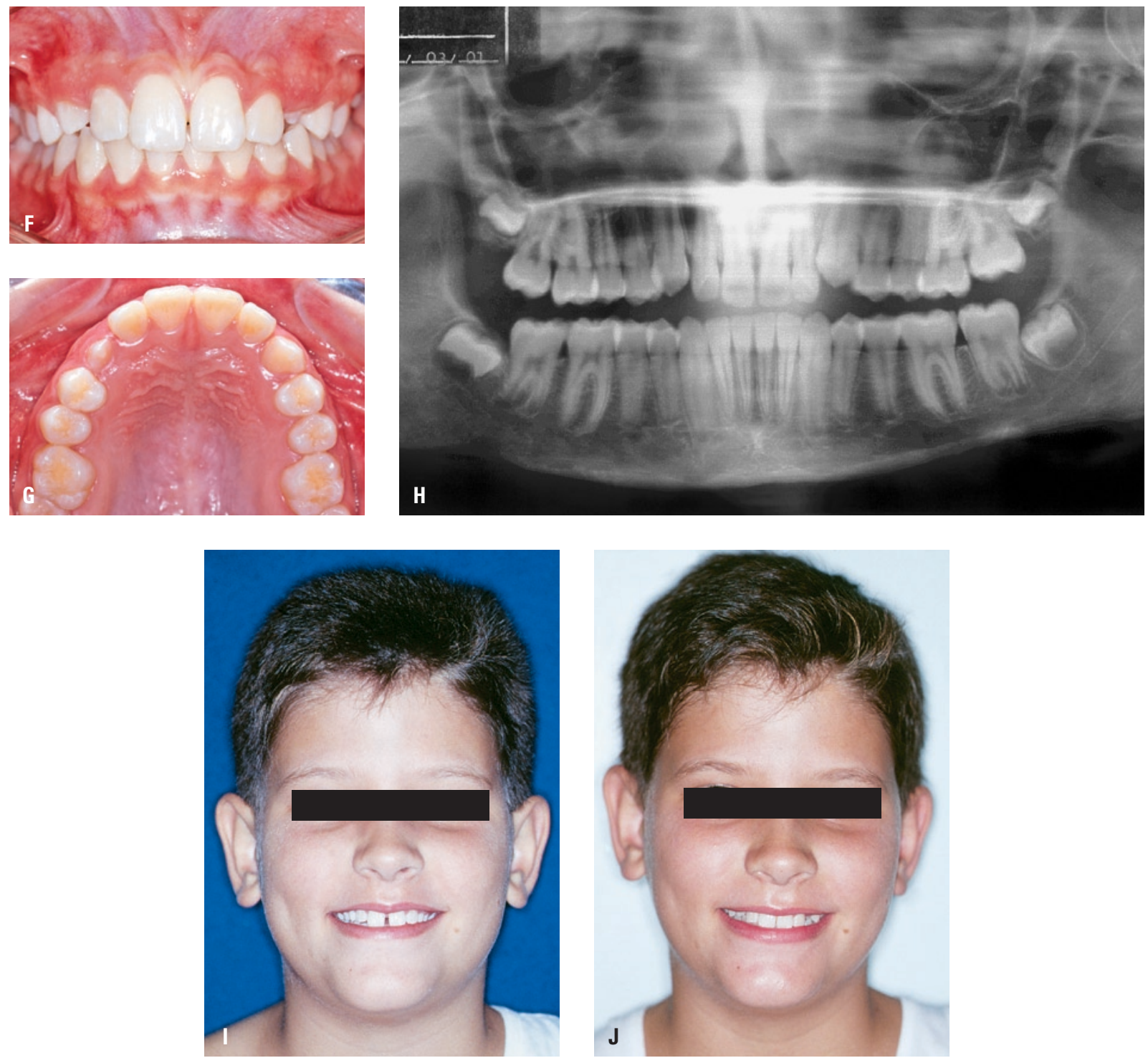

FIGURA 5 A, B, C, D, E, F, G, H, I, J - Fase do patinho feio caracterizada pelo diastema interincisivos centrais superiores e o conseqüente fechamento fisiológico desse espaço, após a irrupção dos caninos permanentes.

entre os incisivos centrais, inclinando suas coroas para distal e criando uma convergência apical, ocorre um aumento demasiado na dimensão do diastema interincisivos (Fig. 7A-G). O transtorno estético imposto ao sorriso da criança justifica a intervenção precoce. A interceptação ortodôntica em tais casos abarca a remoção do hábito e o fechamento do diastema com a concomitante correção da angulação dos incisivos.

E qual o aparelho mais adequado para o fe- chamento do diastema nas duas situações mencionadas acima? Pode-se utilizar aparelhos fixos parciais, com bráquetes colados somente nos incisivos centrais ${ }^{11}$. A força para aproximação dos incisivos pode ser gerada tanto pelo fio de amarrilho conjugado, quanto pelas cadeias elásticas. Nessa fase, empregam-se fios de nivelamento mais delgados (.018') quando deseja-se movimento de inclinação da coroa para mesial e a correção da convergência apical dos incisivos (Fig. 8A-B). Mas se os 


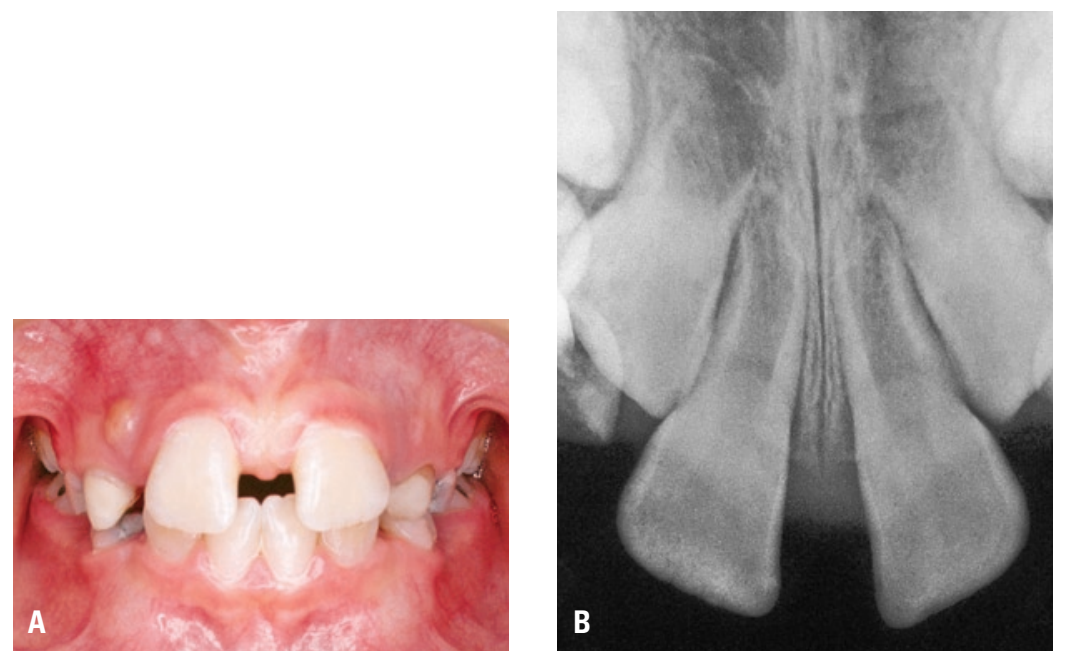

FIGURA 6 A, B, C - Diastema interincisivos centrais superiores e a falta de espaço para irrupção dos incisivos laterais.
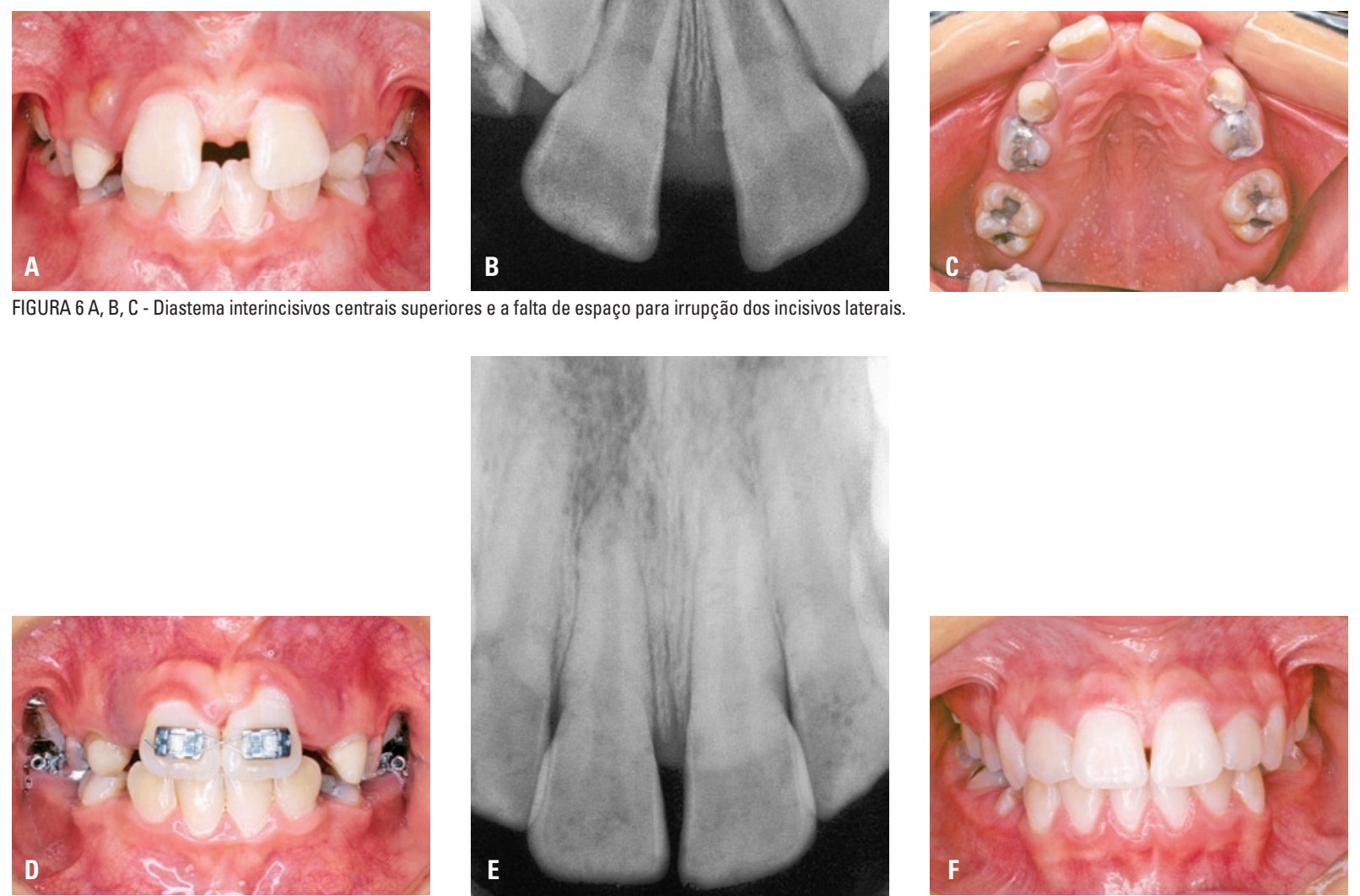

FIGURA 6 D, E, F - Fechamento ortodôntico do espaço e radiografia periapical evidenciando o paralelismo radicular.

incisivos apresentarem-se inicialmente com uma angulação normal, o diastema deve ser fechado no fio retangular .019' x .025' ou .021' x .025', favorecendo o movimento dentário de corpo para mesial (Fig.9A-F). Os aparelhos removíveis com molas (Fig. 10A-I) também podem ser instalados, desde que deseje-se o movimento de angulação dos incisivos para mesial22, 26. Quanto maior a amplitude do diastema, maior a alteração na angulação dentária gerada pelas molas digitais. A superioridade dos aparelhos fixos centra-se no fato do profissional não depender da cooperação do paciente, além da impossibilidade de movimento de jiggling dos incisivos durante o fechamento do diastema. Ao alcançar o resultado desejado, tanto o aparelho fixo quanto o removível devem permanecer como contenção até a irrupção completa dos incisivos laterais.

A literatura parece concorde em não indicar a frenectomia antes do movimento ortodôntico, pois o fechamento do diastema e a compressão da papila interdentária podem funcionar como estímulo para promover a atrofia do tecido fibroso interposto entre os incisivos s,7,8,10,30 $^{\text {. Numa }}$ minoria de pacientes, durante o período de contenção, o profissional pode notar um resultado inverso, a hipertrofia da papila gengival ${ }^{8}$. Nessas situações, antes da remoção da contenção, a 

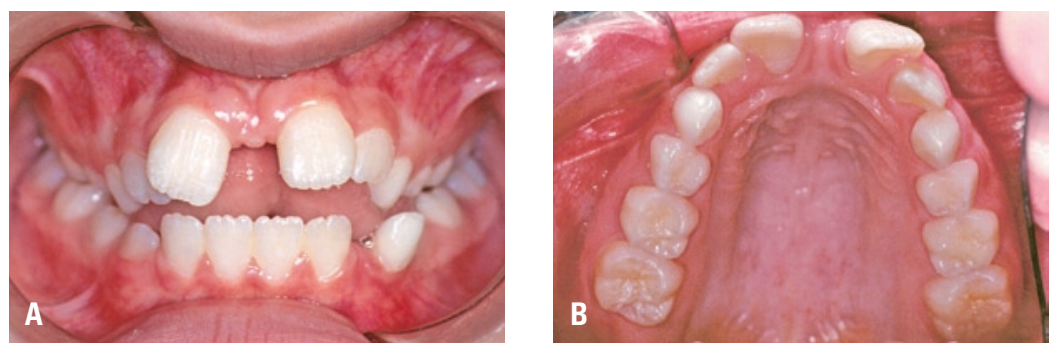

FIGURA 7 A, B - Hábito de sucção com conseqüente má oclusão.
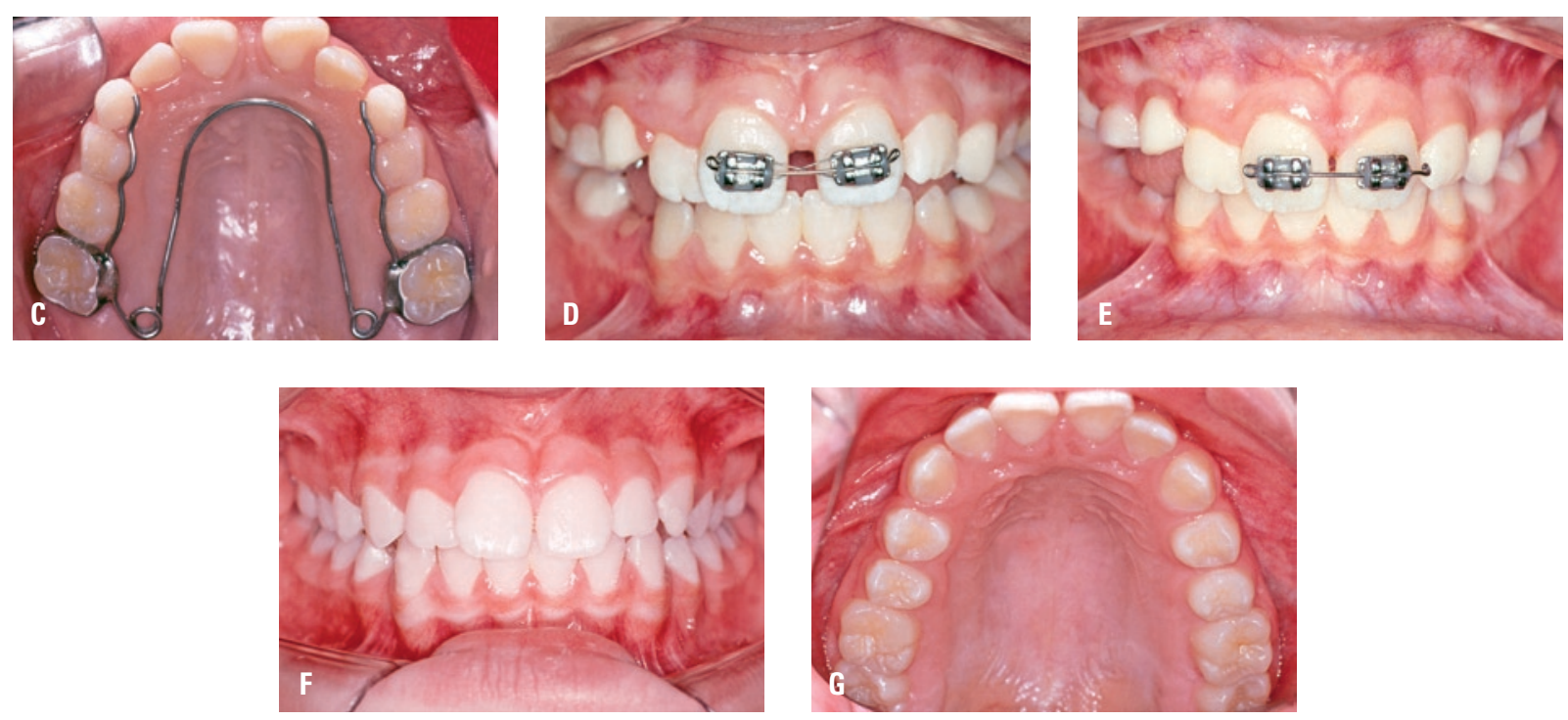

FIGURA 7 C, D, E, F, G - Tratamento ortodôntico para fechamento do diastema.
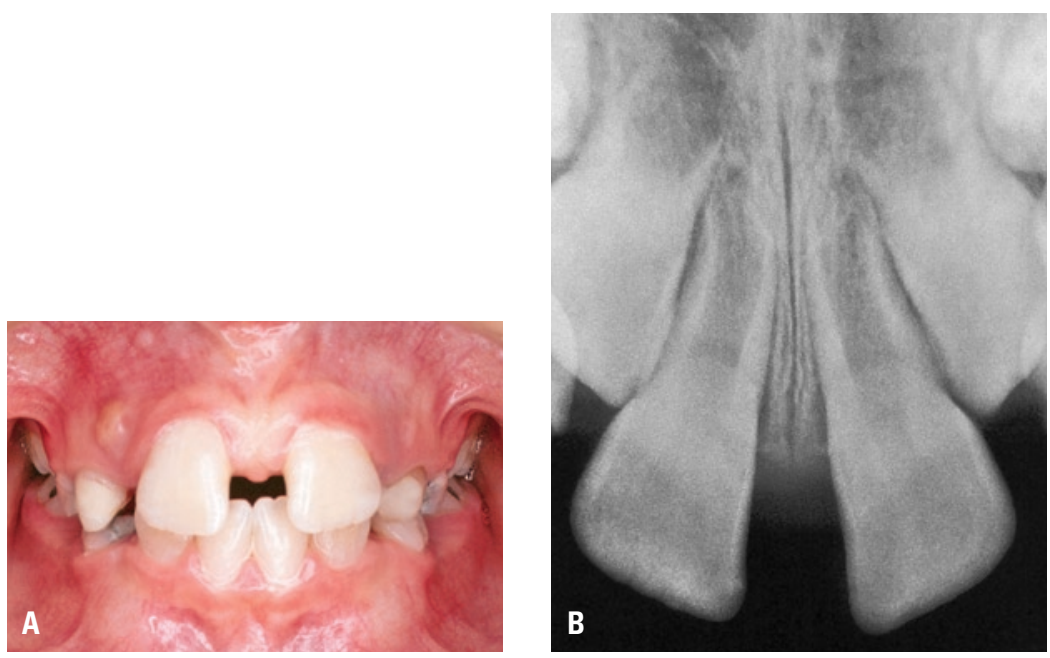

FIGURA 8 A, B - Incisivos centrais contra-angulados com inclinação axial divergente. 

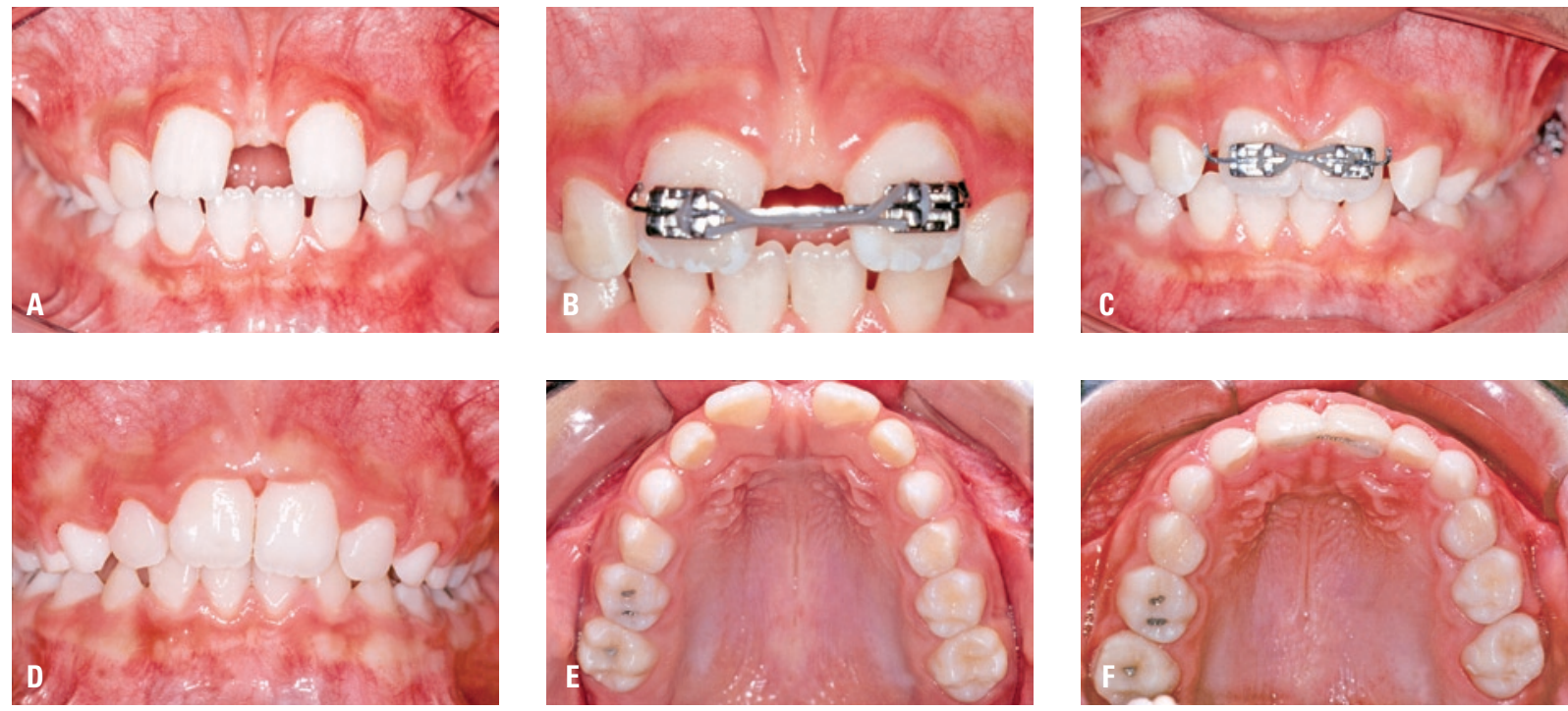

FIGURA 9 A, B, C, D, E, F - Diastema interincisivos centrais com paralelismo axial e fio retangular .021" x .025" para fechamento ortodôntico.
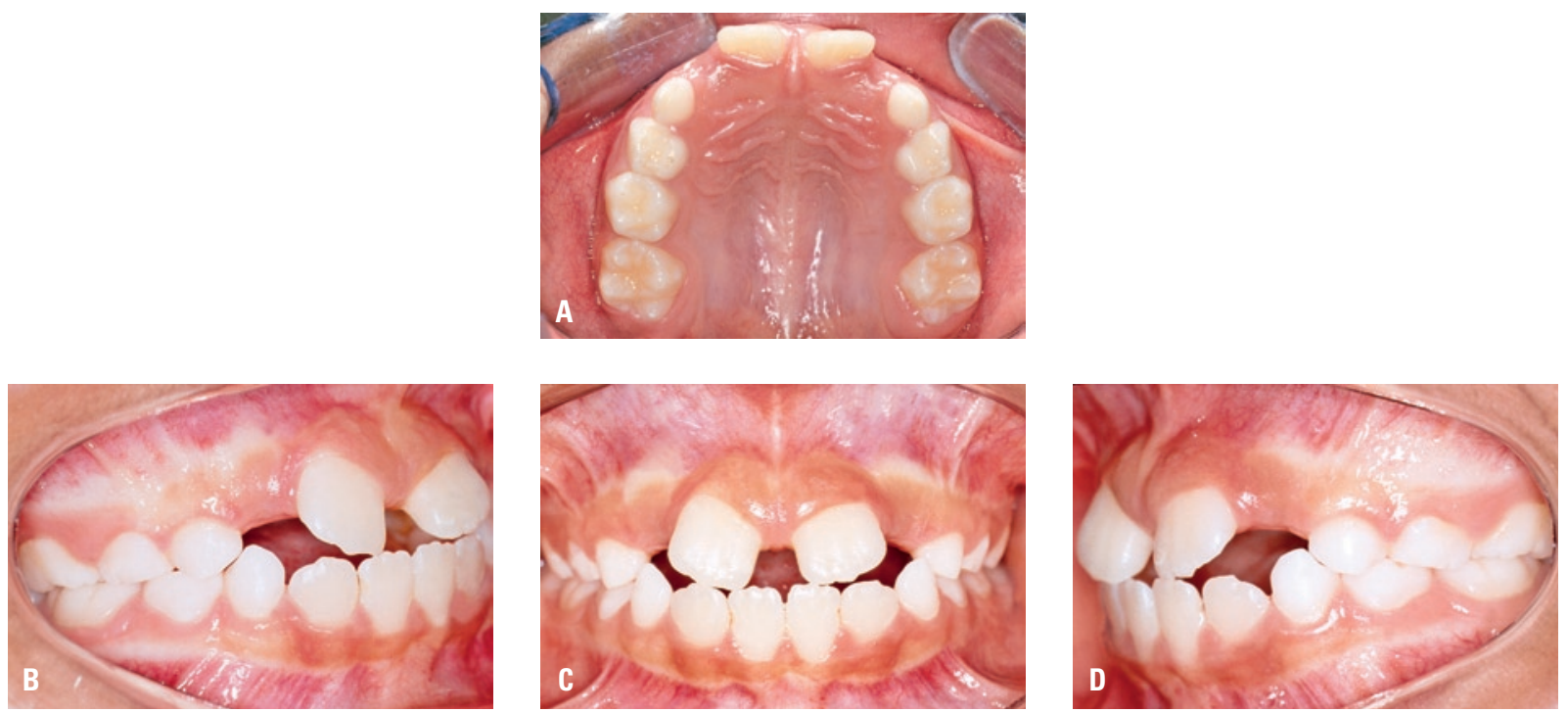

FIGURA 10 A, B, C, D - Diastema interincisivos centrais superiores com divergência das coroas.

criança deve ser encaminhada ao periodontista para realização de frenectomia, favorecendo a estabilidade da interceptação a longo prazo.

Apesar da ausência de trabalhos acerca da estabilidade do fechamento de diastema durante a dentadura mista, a experiência clínica nos revela que, a intervenção precoce não requer contenção definitiva, desde que a intercepta- ção seja acompanhada pela remoção dos hábitos bucais anormais e pela correção cirúrgica de uma eventual hipertrofia gengival interincisivos.

E na dentadura permanente, qual o significado do diastema interincisivos centrais superiores? Os dentes permanentes devem apresentar pontos de contatos cerrados, como rege a $5^{\text {a }}$ 

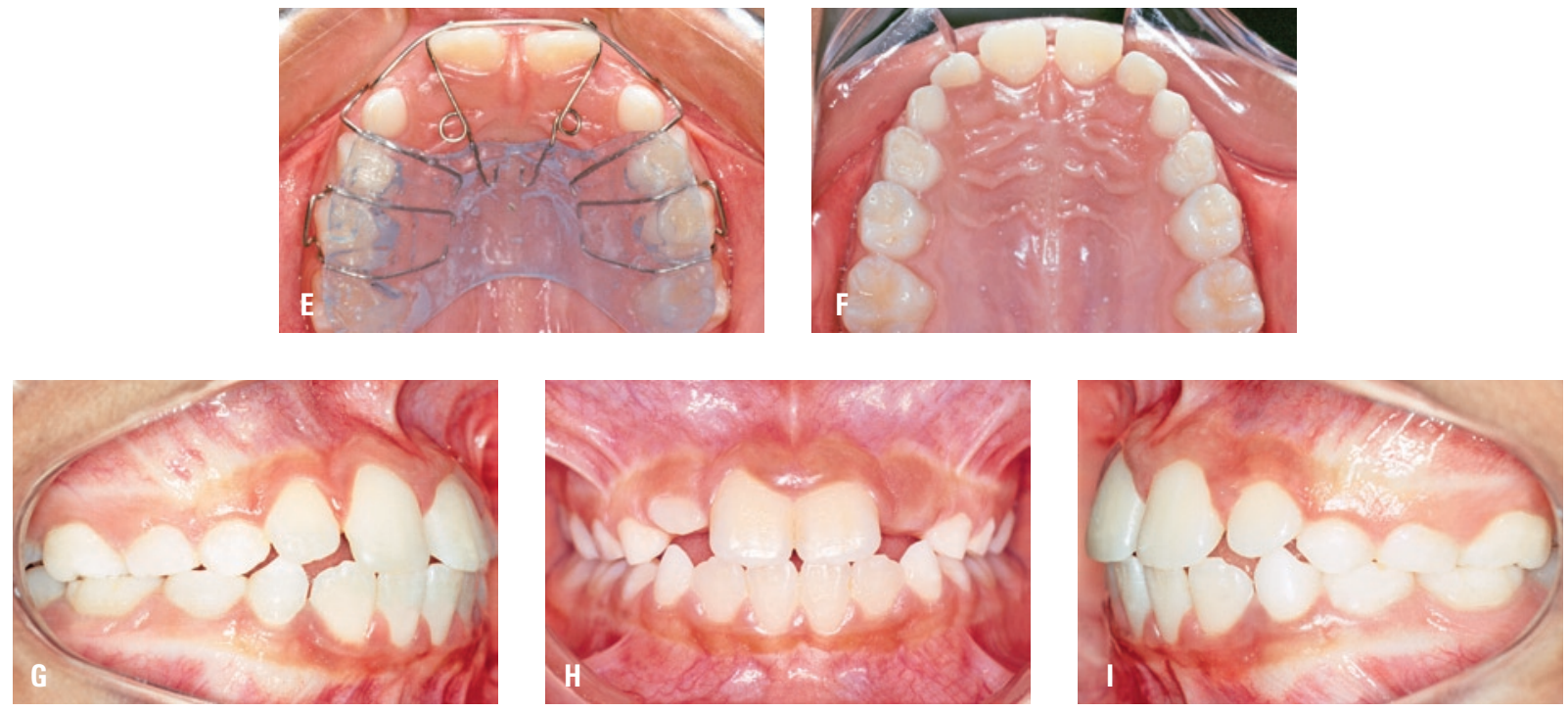

FIGURA 10 E, F, G, H, I - Fechamento do espaço com aparelho ortodôntico removível (molas digitais) e oclusão após o fechamento do diastema e irrupção dos incisivos laterais.

chave da oclusão ideal de Andrews. Portanto, a persistência do diastema mediano na dentadura permanente madura, prevalente em 1,6 a 25,4\% da população $0^{9,15,19,23,27,30}$, denota anormalidade e requer intervenção, principalmente se incomodar o paciente esteticamente.

Voltando-se novamente ao estudo transversal de Taylor $^{30}$, por que em uma pequena porcentagem das crianças o diastema não se fecha espontaneamente, mesmo após a irrupção dos caninos permanentes? A persistência do diastema interincisivos na dentadura permanente apresenta uma

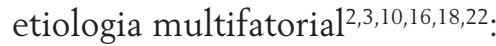

1) Discrepância dente-osso positiva: quando o perímetro do arco dentário excede o somató- rio do diâmetro mesiodistal dos dentes permanentes irrompidos nessa região, o resultado clínico será a presença de múltiplos diastemas ${ }^{14,28}$ (Fig. 11A-C). Sobra espaço ou massa óssea para o alinhamento de todos os dentes permanentes. Possivelmente, o paciente com a dentadura permanente espaçada também mostrará um diastema interincisivos centrais.

2) Agenesia dos incisivos laterais superiores: na ausência congênita dos incisivos laterais, faltará o estímulo natural para o fechamento espontâneo do diastema interincisivos. A força mesial incitada pela irrupção dos caninos superiores permanentes não poderá ser transmitida aos incisivos centrais. Como resultado, o diaste-
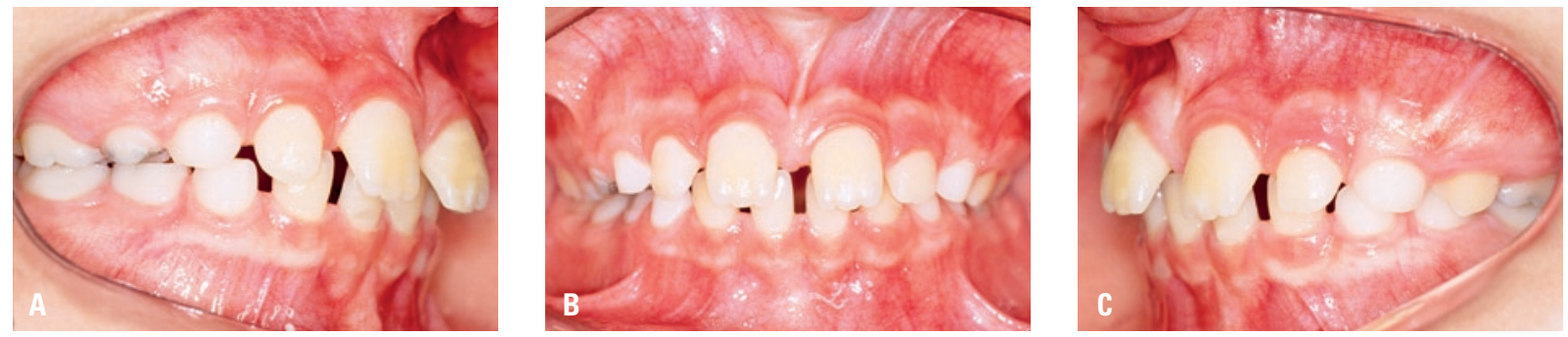

FIGURA 11 A, B, C - Diastemas decorrentes de discrepância dente-osso positiva. 

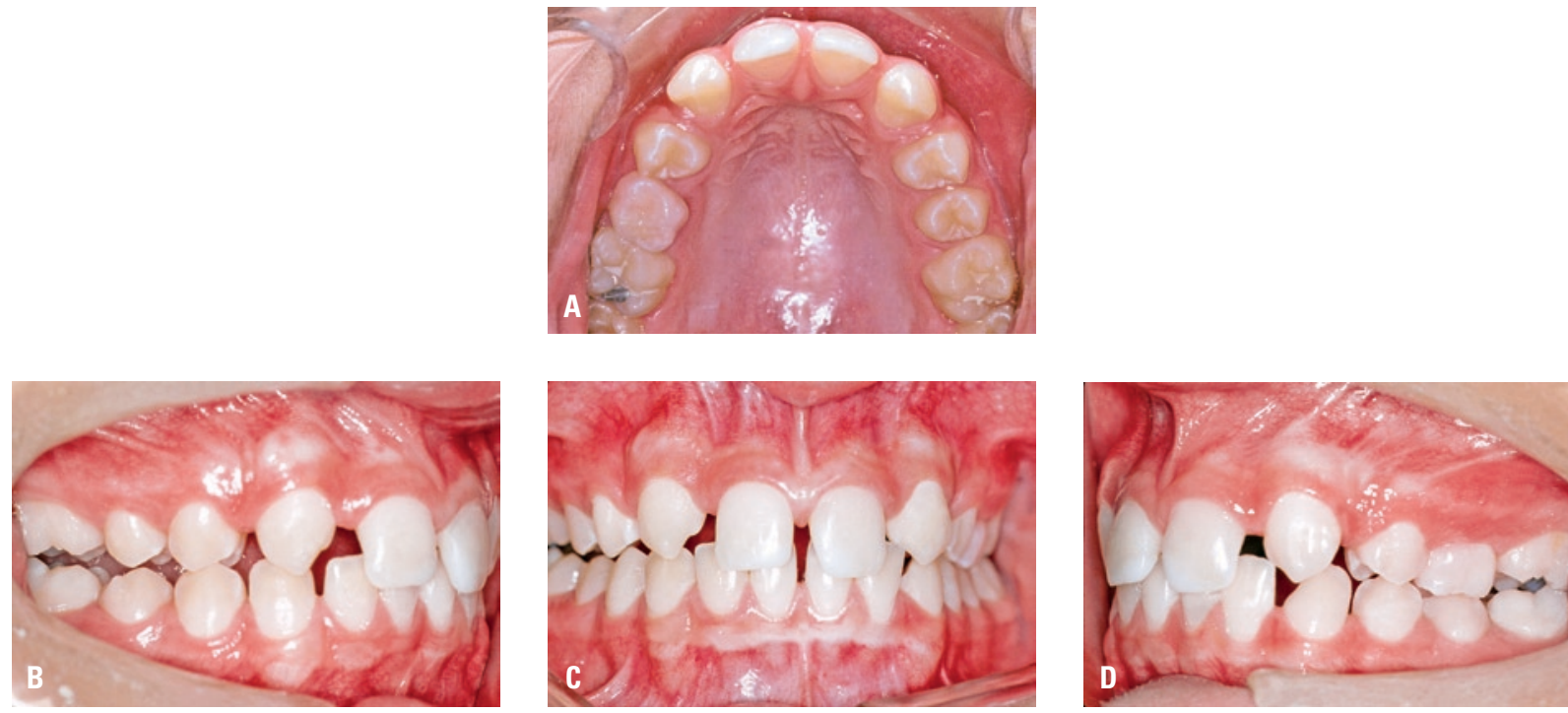

FIGURA 12 A, B, C, D - Ausência congênita dos incisivos laterais superiores e presença de diastemas.
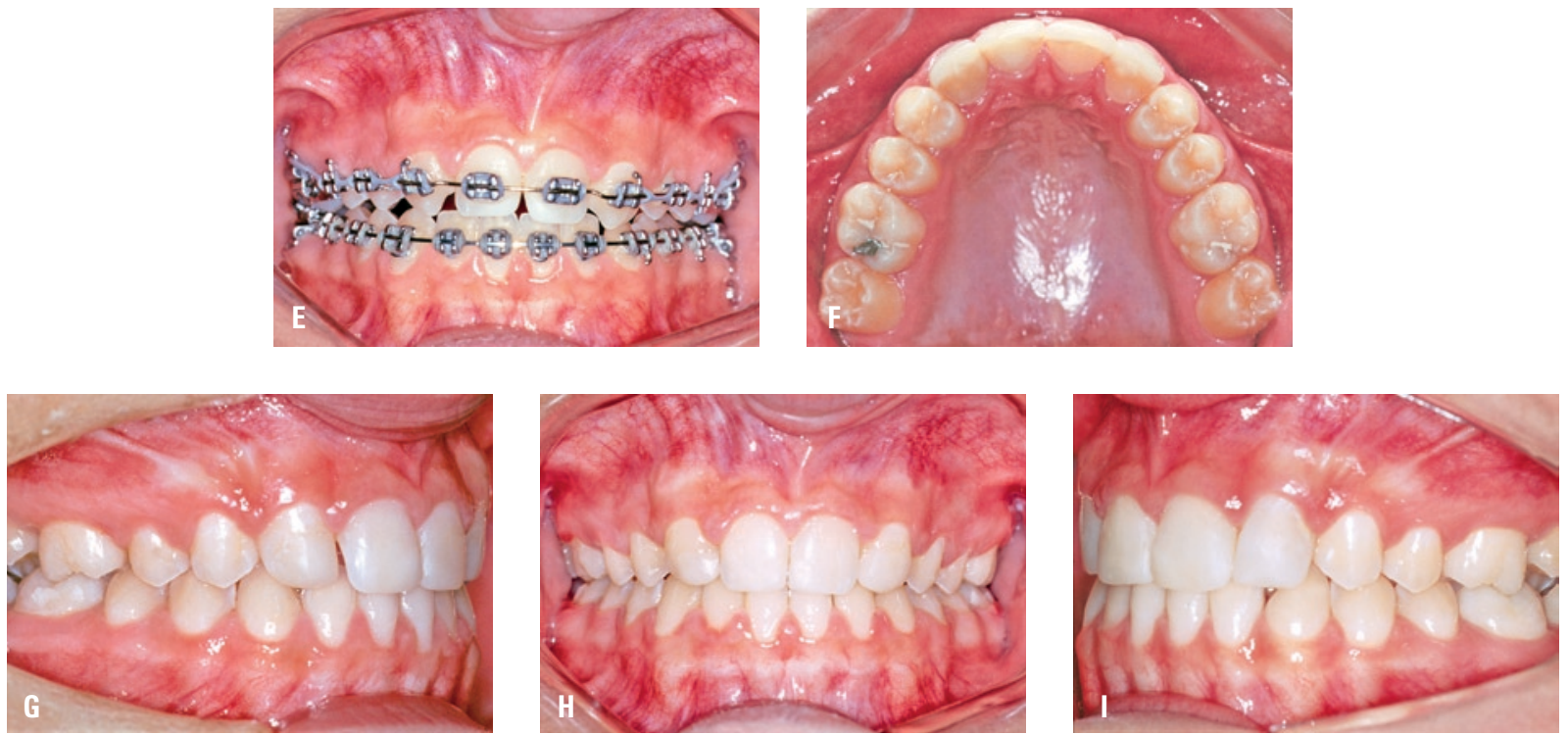

FIGURA 12 E, F, G, H, I - Tratamento ortodôntico e oclusão final após reanatomização provisória dos caninos.

ma mediano não se fecha. Nesses casos pode-se optar pela manutenção do espaço para a colocação de um implante /prótese ou pelo fechamento ortodôntico com os caninos reanatomizados em incisivos laterais (Fig. 12A-I).

3) Microdontia dos incisivos laterais superiores: a manifestação incompleta do gene que determina a agenesia do incisivo lateral, redunda em sua microdontia ${ }^{17}$. Se a deficiência na dimensão mesiodistal dos incisivos laterais for o suficiente para ocasionar uma discrepância dente-osso positiva, provavelmente a irrupção dos caninos superiores não redundará no fechamento espontâneo do diastema interincisivos (Fig. 13A-O). Ademais, a microdontia dos incisivos laterais cria uma discrepância de Bolton com falta de massa dentária no arco superior. Nessas circunstâncias, existem duas opções de 

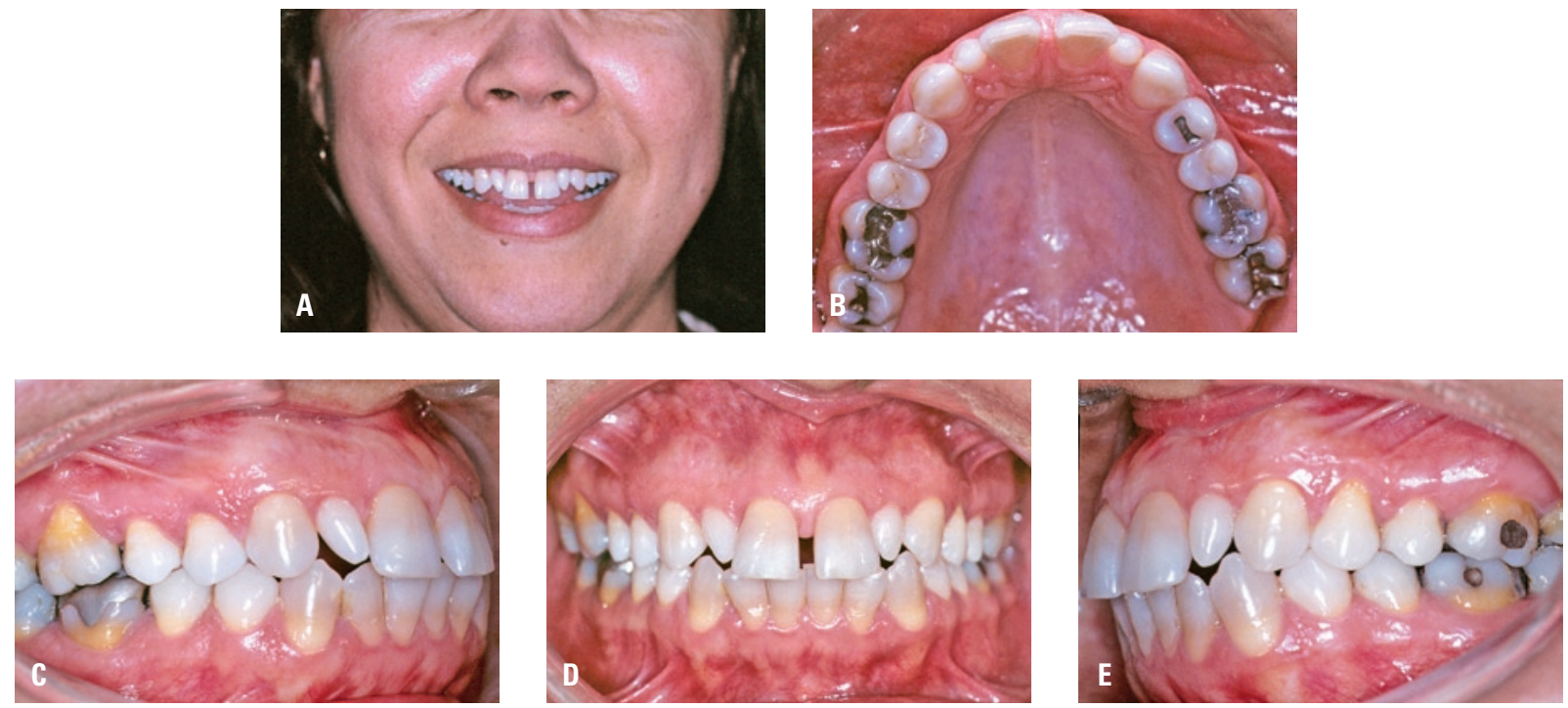

FIGURA $13 \mathrm{~A}, \mathrm{~B}, \mathrm{C}, \mathrm{D}, \mathrm{E}$ - Microdontia bilateral dos incisivos laterais superiores e o conseqüente diastema interincisivos centrais superiores.
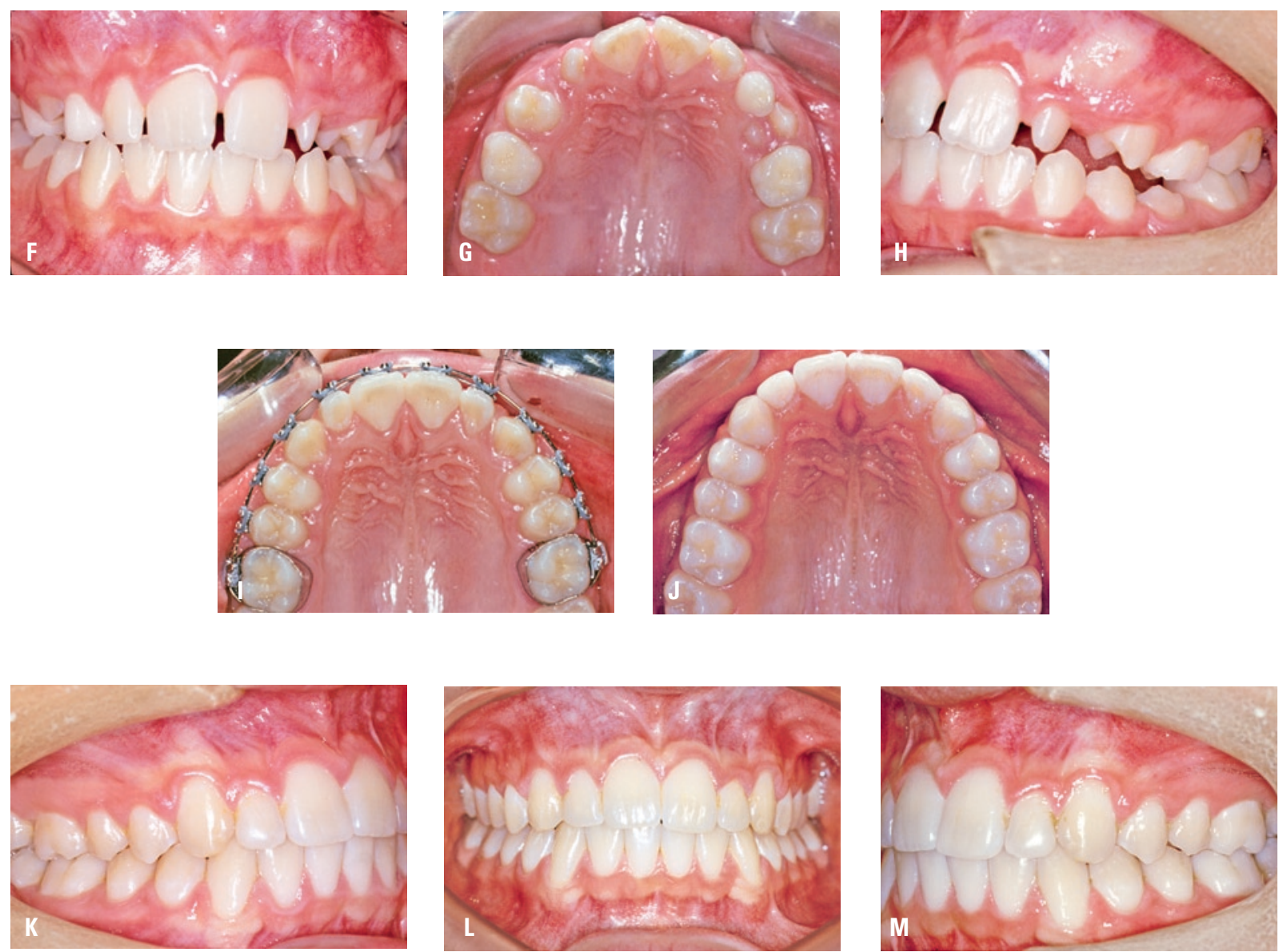

FIGURA 13 F, G, H, I, J, K, L, M, - Caso clínico evidenciando microdontia do incisivo lateral superior esquerdo, presença de diastemas e 0 aspecto final do tratamento ortodôntico e a respectiva oclusão. 

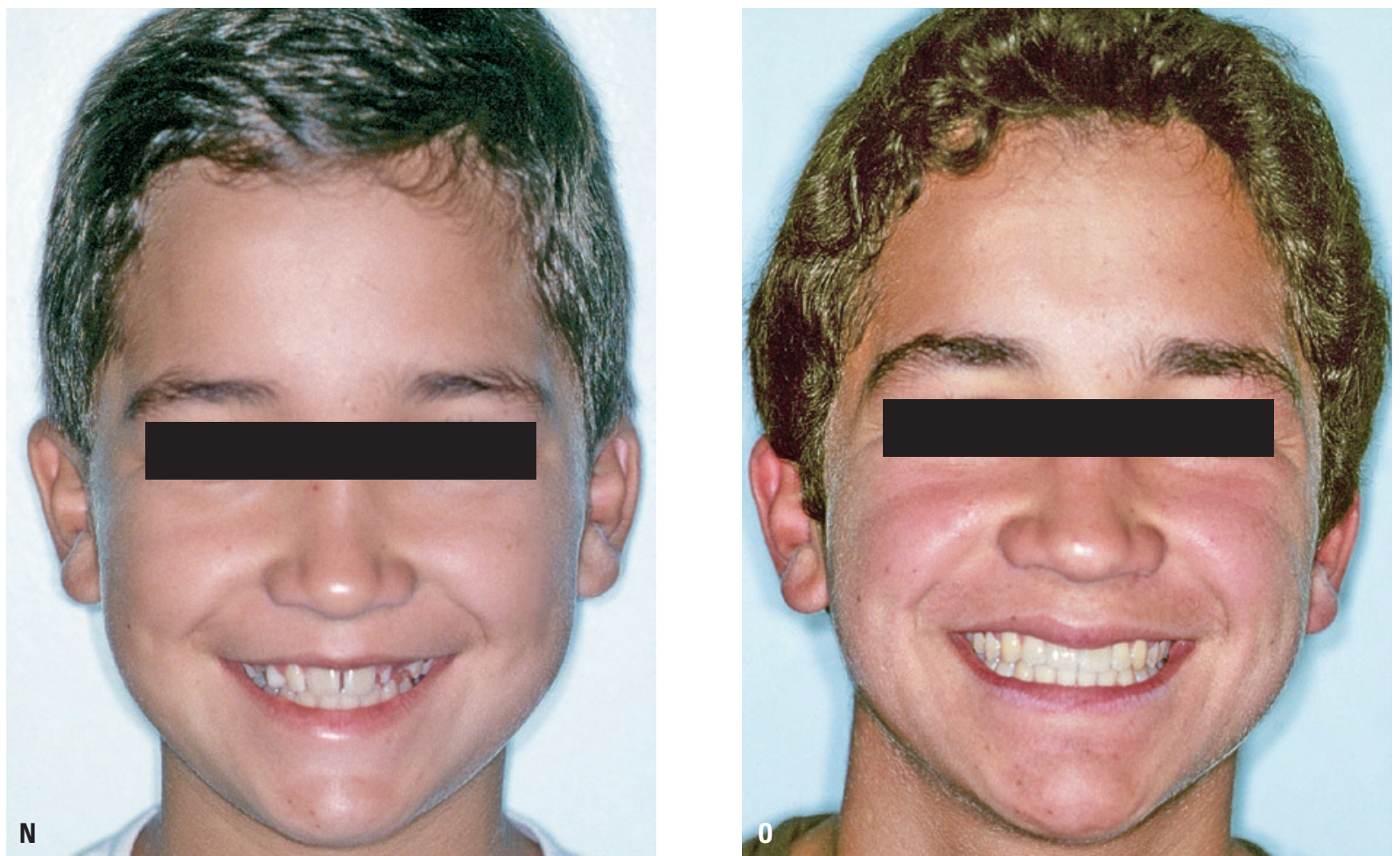

FIGURA 13 N, 0 - Caso clínico evidenciando microdontia do incisivo lateral superior esquerdo, presença de diastemas e 0 aspecto final do tratamento ortodôntico e a respectiva oclusão.

tratamento. $\mathrm{Ou}$ implementa-se o fechamento dos diastemas com os sistemas restauradores adesivos, ou então ortodonticamente, com desgastes interproximais compensatórios dos incisivos inferiores. Em suma, ou aumenta-se a massa dentária superior ou reduz-se a massa dentária inferior.

4) Hereditariedade: a constatação do diastema interincisivos, em diversas pessoas de uma mesma família, já havia sugerido a influência genética na expressão de tal característica. Mas a busca incessante por novos conhecimentos e o desenvolvimento da biologia genética produziram preciosas evidências. A discrepância denteosso parece apresentar uma etiologia predominantemente genética, uma vez que as dimensões das coroas dentárias são determinadas pela herança ${ }^{17}$. Além disso, estudos em gêmeos e em familiares revelou a tendência genética da hipodontia $^{17}$. Metade dos irmãos gêmeos e dos pais de crianças com agenesias também apresentaram tal irregularidade, enquanto a prevalência na população em geral equivale a aproximadamente $5 \%{ }^{15}$. Se a discrepância dente-osso positiva, assim como a agenesia e a microdontia, são determinadas geneticamente, e por sua vez, constituem um dos fatores causais dos diastemas como discutido acima, percebe-se a amplitude da herança em sua etiologia. Recentemente, ao analisar 30 famílias norte-americanas, Gass e outros ${ }^{9}$ sugeriu o modo autossômico dominante de hereditariedade do diastema mediano (Fig. 14A-B).

5) Hábitos: não somente os fatores genéticos, mas também os ambientais, podem determinar a persistência do diastema interincisivos centrais superiores. Neste contexto, inseremse os hábitos bucais deletérios de sucção e o pressionamento lingual atípico. O dedo ou a chupeta, durante a sucção, interpõe-se entre os incisivos superiores e inferiores, restringindo a 
irrupção destes dentes, enquanto os dentes posteriores continuam a desenvolver-se no sentido vertical. Conseqüentemente, determina-se uma mordida aberta, quase sempre restrita à região anterior dos arcos dentários, de forma circular e bem circunscrita ${ }^{2,18}$. O contato do objeto sugado com o palato desaloja a língua que se mantém numa posição mais inferior, afastando-se do contato com os dentes póstero-superiores. Esta alteração, somada à força de sucção desempenhada pelo músculo bucinador, ocasiona a atresia do arco dentário superior, culminando

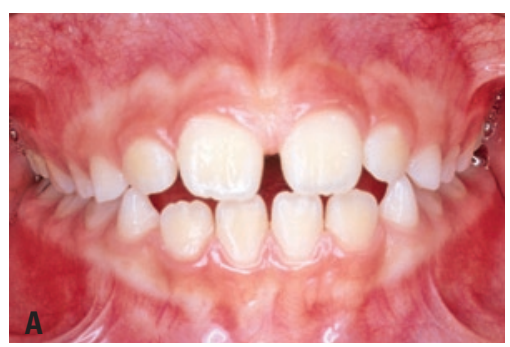

FIGURA 14 A, B - Diastemas hereditários.

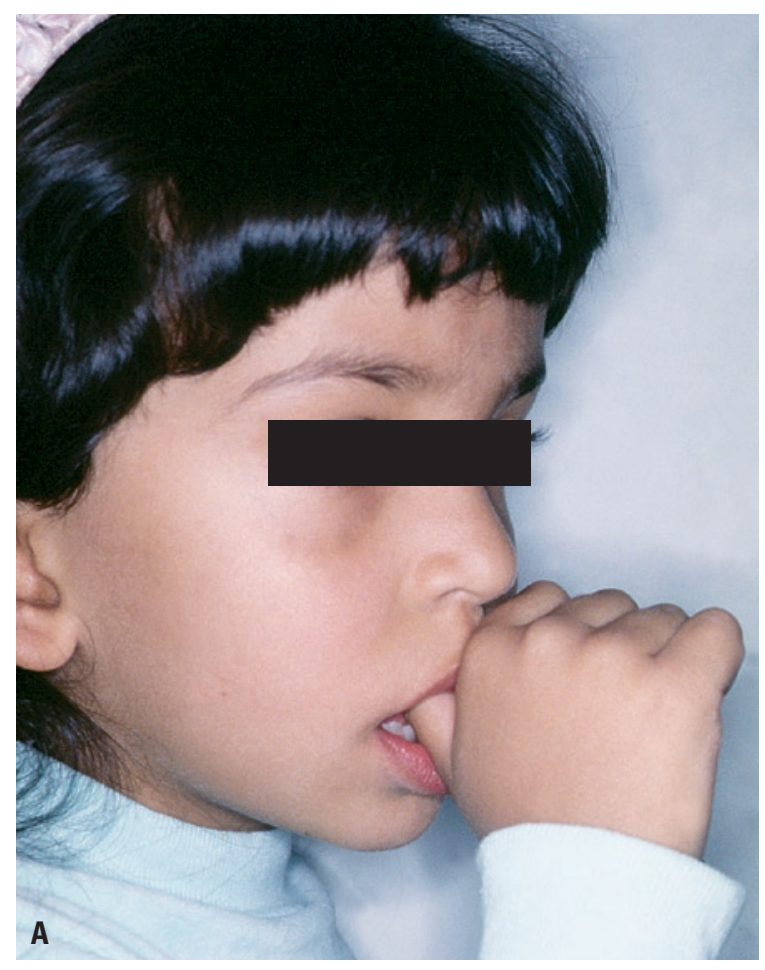

FIGURA 15 A, B - Sucção de polegar e diastema correspondente. na mordida cruzada posterior uni ou bilateral. Ademais, o hábito prolongado de sucção, se estiver atuando durante a dentadura mista, pode funcionar como obstáculos mecânicos ao fechamento espontâneo do diastema mediano (Fig. 15A-B), principalmente se a criança alojar o dedo ou a chupeta entre os incisivos centrais. O hábito de sucção também pode atuar indiretamente na manutenção do diastema ao ocasionar uma inclinação vestibular acentuada dos incisivos superiores, aumentando o perímetro do arco superior. A interposição da língua
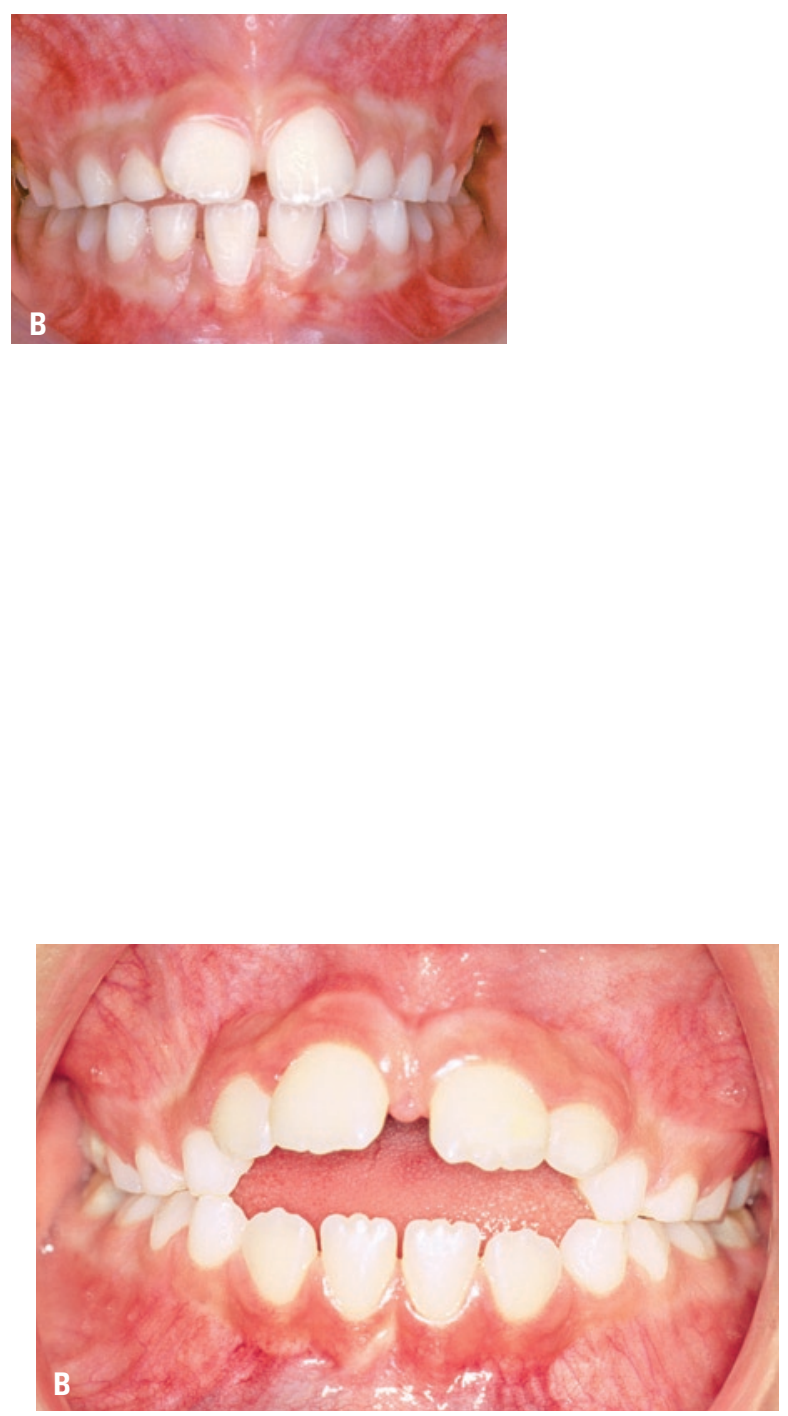

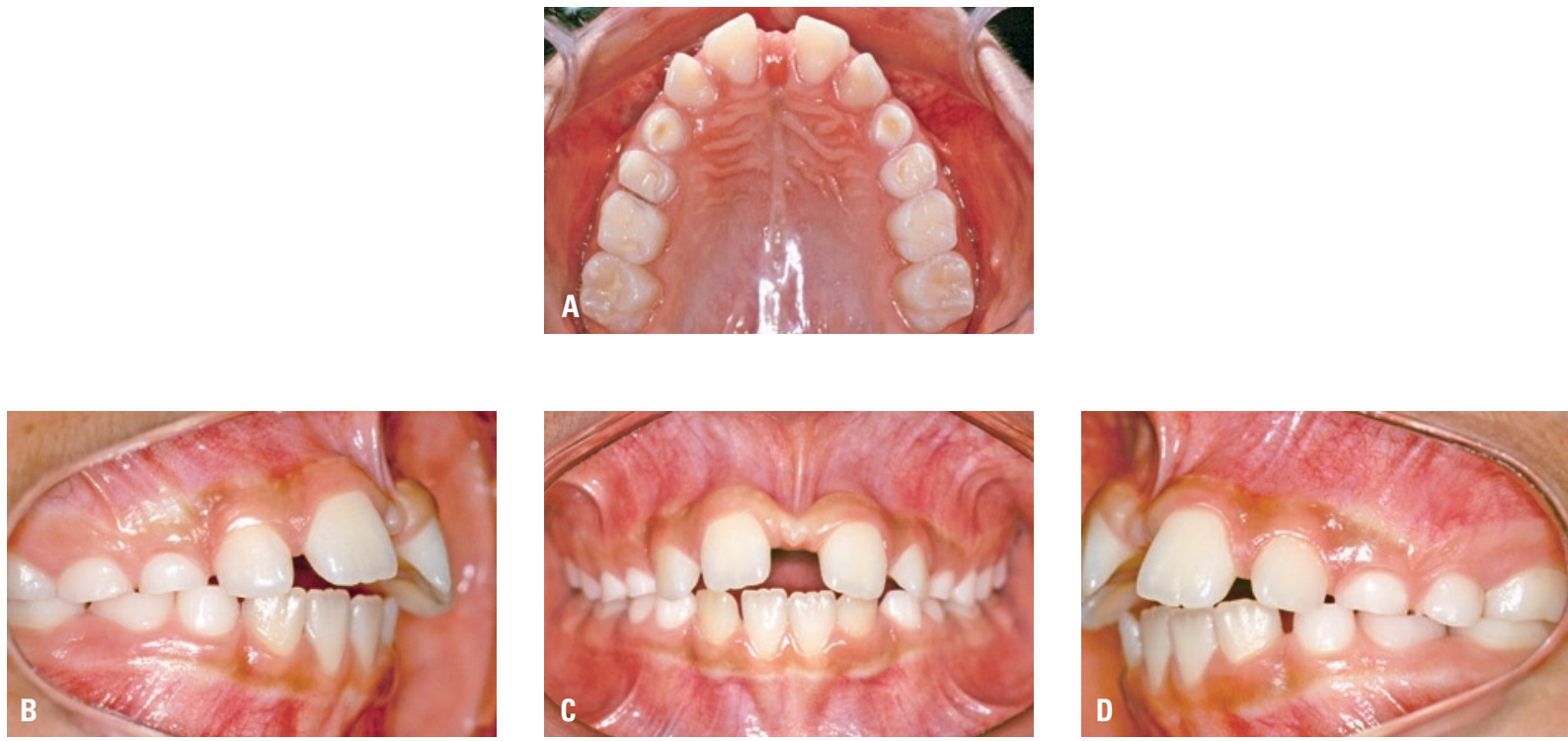

FIGURA 16 A, B, C, D - Paciente apresentando deglutição atípica com interposição lingual e a má oclusão correspondente incluindo diastema mediano.
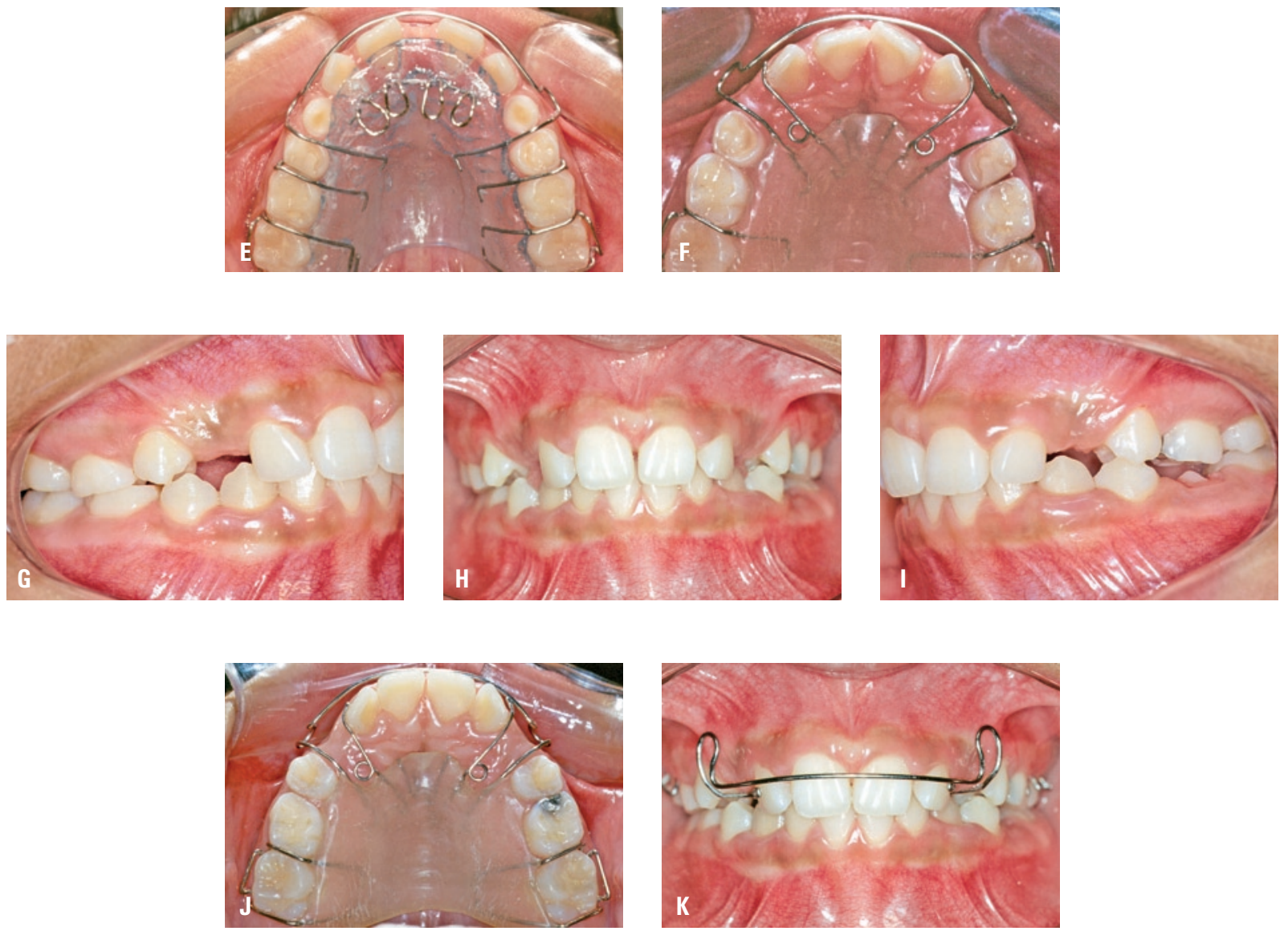

FIGURA 16 E, F, G, H, I, J, K - Grade palatina removível impedidora de língua e aparelho ortodôntico removível com molas digitais para fechamento do diastema. 

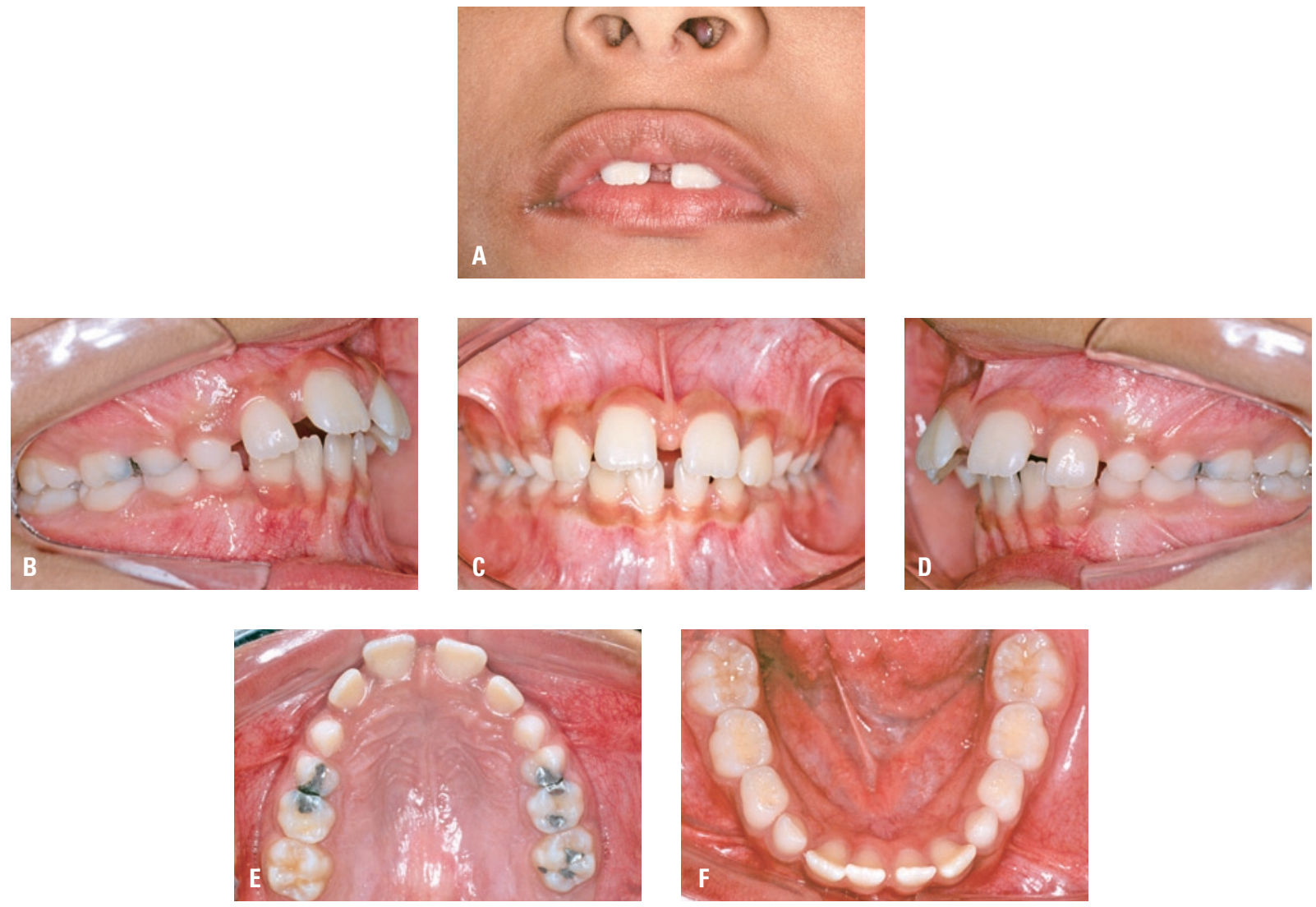

FIGURA 17 A, B, C, D, E, F - Paciente com hábito de interposição do lábio inferior e a respectiva má oclusão com diastemas nas regiões ântero-superior e inferior, vestibularização dos incisivos superiores e trespasses horizontal e vertical aumentados.

entre os arcos dentários durante a fonação, deglutição e mesmo durante o repouso ou postura, constitui uma anormalidade funcional denominada pressionamento lingual atípico. Este hábito pode ocasionar, além da mordida aberta anterior, uma inclinação vestibular acentuada dos incisivos superiores e inferiores, gerando diastemas generalizados na região anterior ${ }^{2}$ (Fig. 16A-K). Da mesma forma o hábito de sucção do lábio inferior, vestibulariza os incisivos superiores criando diastemas nesta região, verticaliza os incisivos inferiores aumentando os trepasses horizontal e vertical (Fig. 17A-H).

6) Supranumerário mesiodens e patologias: um dente localizado ou irrompido entre os incisivos centrais superiores (Fig. 18A-I), assim como patologias na região mediana da pré-maxila, certamente funcionarão como impedimento físico para o cerramento fisiológicos do diastema mediano.

7) Freio labial: o diastema mediano persistente na dentadura permanente pode mostrar-se combinado a um freio labial superior hipertrófico. Devido a essa associação, a Odontologia, nas décadas iniciais do século passado, via no freio labial o fator etiológico primordial do diastema interincisivos na dentadura permanente. A frenectomia preventiva era um procedimento realizado rotineiramente. Em meados dos anos 40 e 50, uma análise crítica de diversos estudiosos começou a modificar a interpretação do freio labial. Atentemos para o desenvolvimento normal desta estrutura anatômica ${ }^{8}$. No $3^{\circ}$ mês de vida 

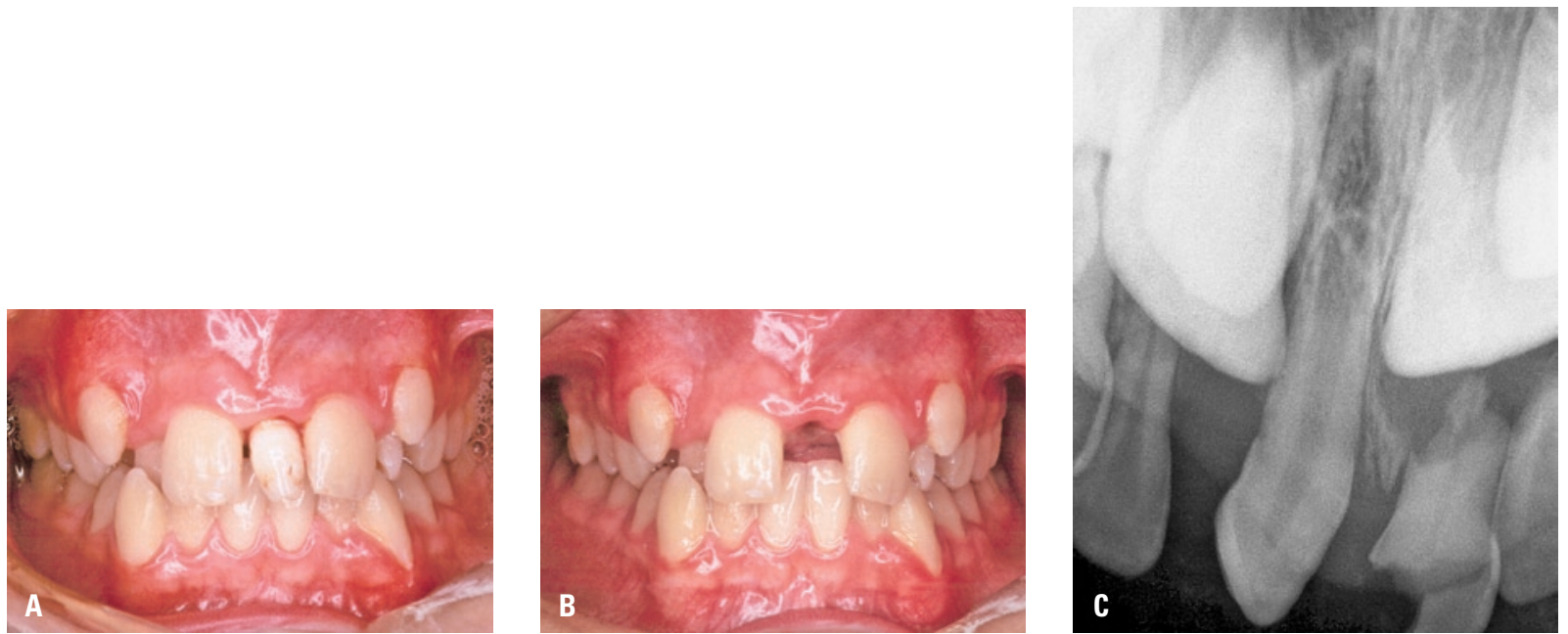

FIGURA 18 A, B, C - Presença de supranumerários intra-ósseo e irrompido, mantendo diastema interincisivos.
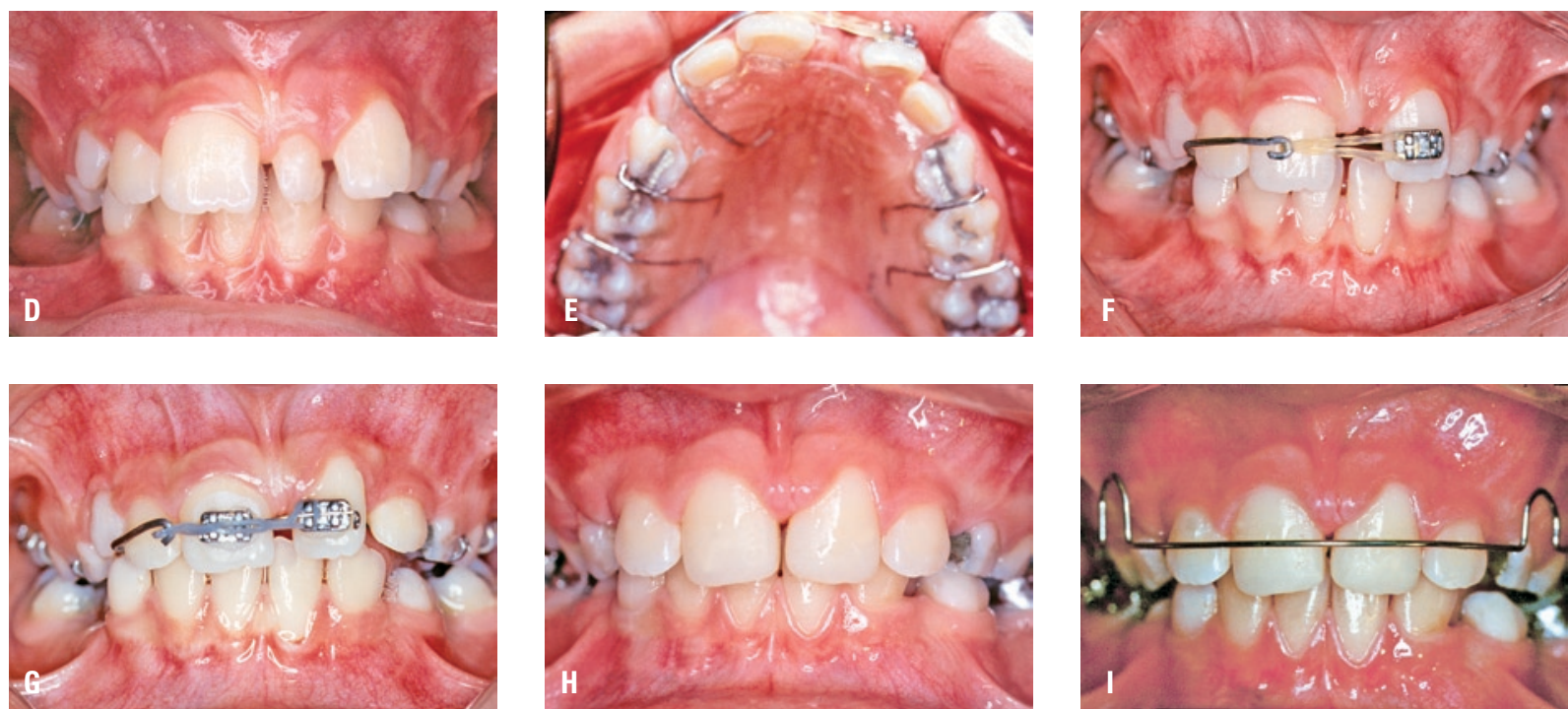

FIGURA 18 D, E, F, G, H, I - Tratamento ortodôntico interceptador, oclusão final com reanatomização provisória do incisivo central esquerdo (microdontia) e placa de Hawley como contenção.

intra-uterina, o freio labial superior apresenta-se bastante volumoso e extenso, insere-se profundamente na papila palatina, sulcando e dividindo o arco alveolar em duas partes. Entretanto, o freio apresenta uma tendência à remissão ao longo da vida ${ }^{21}$. O crescimento vertical do rebordo alveolar excede o desenvolvimento do freio, de modo que ao nascimento, o cordão fibroso insere-se mais superficialmente, e nas imediações da crista óssea alveolar. Embora bem menor, nesta fase ainda aparenta estar unido à papila incisiva. Com a irrupção dos dentes decíduos e a continuidade do desenvolvimento vertical dentoalveolar, observa-se um deslocamento gradual da inserção fibrosa para a superfície vestibular. Possivelmente, não é o freio que migra, ele mantém-se estacionado enquanto dentes e processo alveolar crescem e deslocam-se para baixo. Com a irrupção dos incisivos permanentes e a continuidade do processo de atrofia do freio, ele 
alcança agora sua posição normal, inserindo-se acima da papila gengival interproximal. Se, ainda nesta fase, o freio apresentar uma inserção baixa (variação da normalidade), a subseqüente irrupção dos incisivos laterais e dos caninos superiores, assim como o fechamento espontâneo do diastema interincisivos centrais, estimulará sua atrofia por pressionamento. No entanto, Graber ${ }^{10}$ enfatizou que, com a manutenção do diastema na dentadura permanente, devido a qualquer um dos fatores etiológicos citados nos itens 1 a 6 , o freio labial superior pode manterse inserido inferiormente, dificultando a identificação da real participação da inserção fibrosa na persistência do diastema (Fig. 19A-B). Surge então a discussão semelhante ao ovo e à galinha. Quem veio primeiro? Possivelmente o freio labial hipertrófico represente a conseqüência, e não a causa, da manutenção do diastema ${ }^{2,5,7,8,10}$, 12,30. E calcado nessas evidências, hodiernamente condena-se a frenectomia preventiva, realizada em estágios precoces do desenvolvimento oclu-
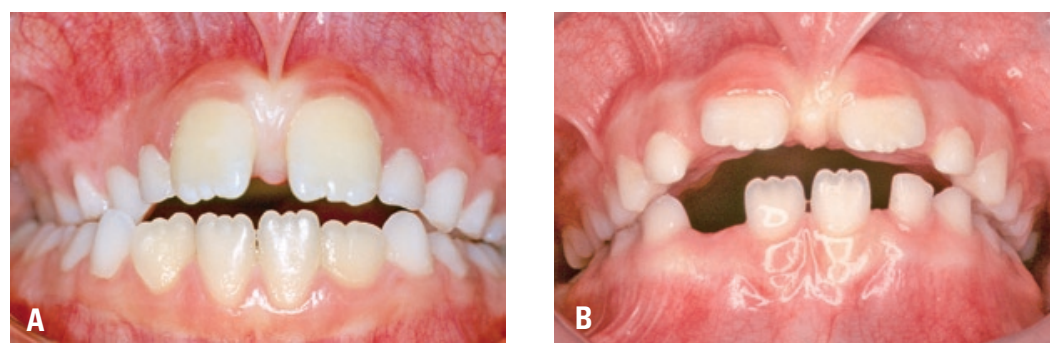

FIGURA 19 A, B - Freio labial hipertrófico e presença de diastema.
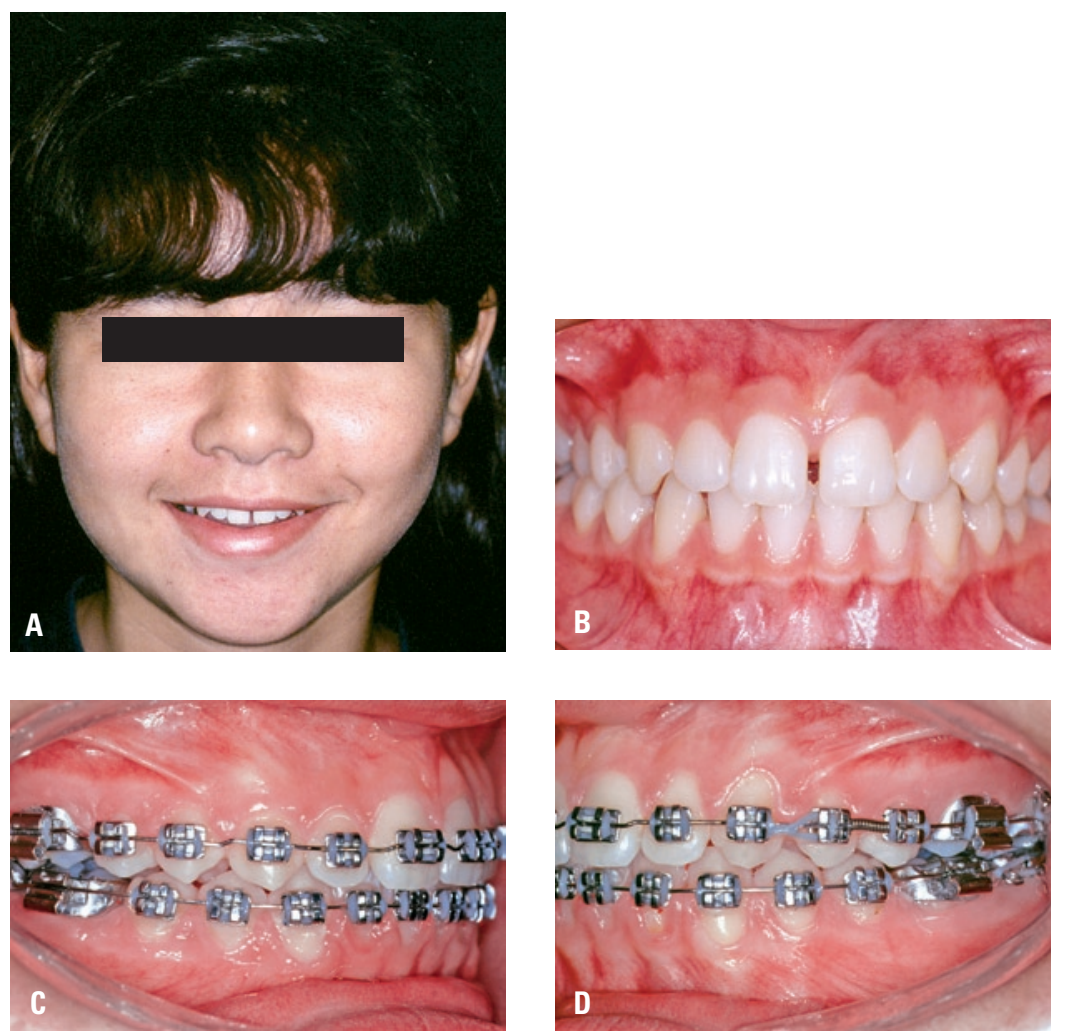

FIGURA 20 A, B, C, D, E, F, G, H - Dentadura permanente com diastema e tratamento ortodôntico corretivo. 

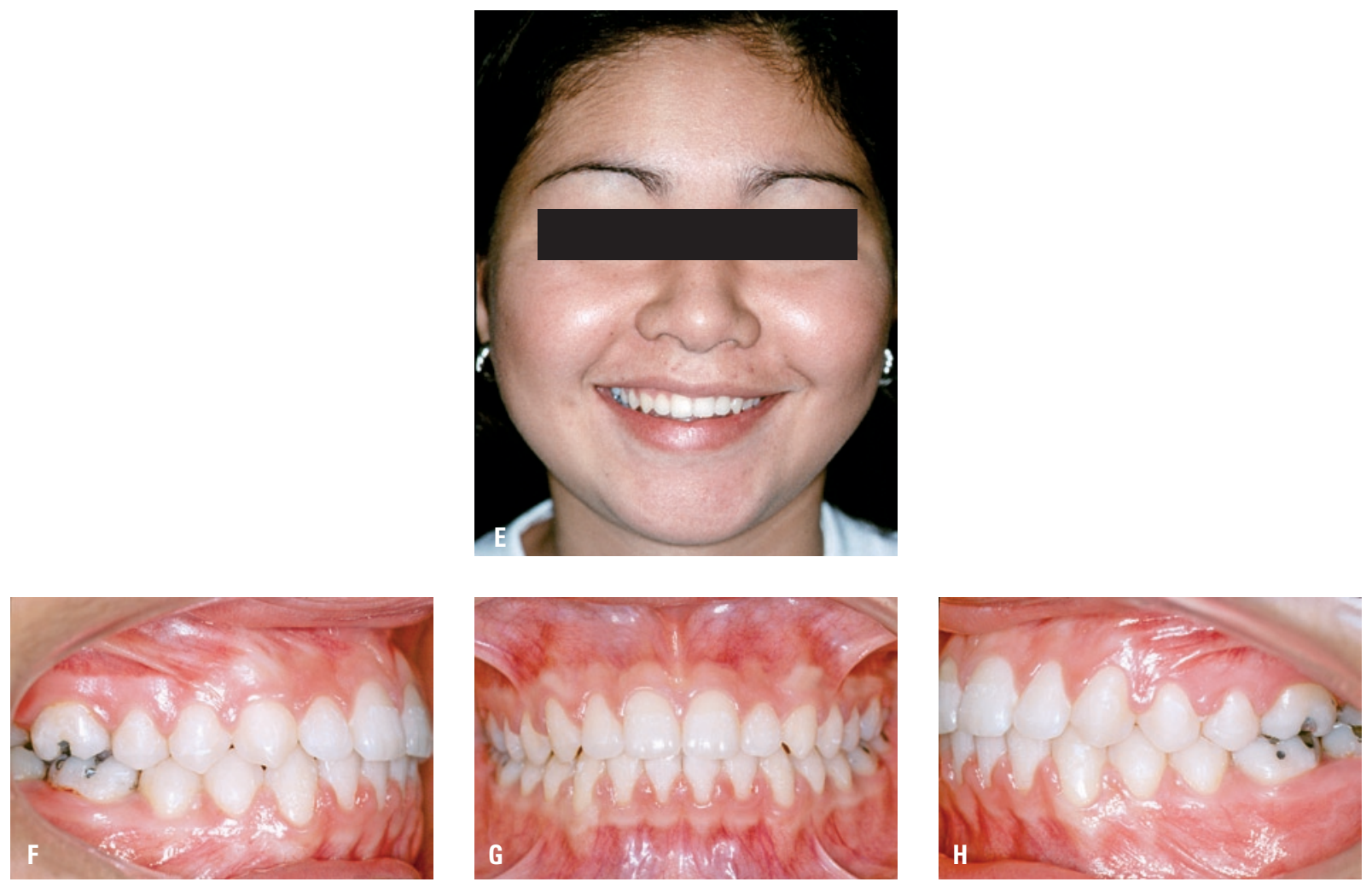

FIGURA $20 \mathrm{E}, \mathrm{F}, \mathrm{G}, \mathrm{H}$ - Aspecto final e a respectiva oclusão.

sal. Seguindo a mesma linha de raciocínio, ao fechar um diastema na dentadura permanente, a minoria dos ortodontistas requisita uma frenectomia prévia. A aproximação mecânica dos incisivos centrais superiores, mesmo no adulto, pode estimular a atrofia do freio labial, quando presente. Como na dentadura mista, poucos pacientes necessitarão a frenectomia pós-fechamento, ditado pela ocorrência de hipertrofia da papila interdentária.

Se por um lado, na dentadura permanente, o fechamento ortodôntico do diastema mediano não impõe grandes dificuldades (Fig. 20A-H), por outro a estabilidade da correção parece bastante crítica. Um estudo longitudinal ${ }^{29}$ apontou a reabertura do diastema em 34\% dos casos. E a recidiva não foi previsível segundo as características iniciais do paciente, incluindo a presença de freio labial anormal. Portanto, sempre se recomenda uma contenção fixa e definitiva após o fechamento de diastemas neste estágio do desenvolvimento oclusal. 


\title{
The maxillary interincisal diastema: How and when treat?
}

\begin{abstract}
Nowadays, the diastemas between the upper central incisors are an antiaesthetic factor being greatly prejudicial in a social aspect. The differential diagnosis of this anomaly of occlusion must be realized as earlier as possible, not only to orientate the patients and their parents, but also to do the correct treatment, providing a pleasant esthetic and social comfort. In fact, the median diastema is considered a normal characteristic during the childhood and with the development of the occlusion there is a consequent physiological closure. The maintenance of these diastemas, depending on the etiology, that is multifactorial and normally related to a positive tooth-bone discrepancy, microdontia, upper lateral incisors agenesis, deleterious habits, erupted or intrabony supernumerary tooth, heredity, hypertrophic labial frenum and others. The main objective of this paper is to provide the necessary information to the reader about when (the right time) and how to manage for closing this space.
\end{abstract}

Key words: Diastema. Labial frenum. Etiology. Orthodontic treatment.

\section{REFERÊNCIAS}

1. ALMEIDA, R. R. et al. Ortodontia preventiva e interceptora: mito ou realidade? R Dental Press Ortodon Ortop Facial, Maringá, v. 4, n. 6, p. 87-108, nov./dez. 1999.

2. ALMEIDA, R. R. et al. Etiologia das más oclusões: causas hereditárias e congênitas, adquiridas gerais, locais e proximais (hábitos bucais). R Dental Press Ortodon Ortop Facial, Maringá, v. 5, n. 6, p.107-129, nov./dez. 2000

3. ARAÚJO, L. G.; BOLOGNESE, M. A. Diastema interincisal $x$ freio labial anormal. RBO, Rio de Janeiro, n. 5, p.20-28, set./out. 1983.

4. ARAÚJO, M. C. M. Ortodontia para clínicos. 4. ed. São Paulo. Ed. Santos, 1988.

5. BEDELL, W. R. Nonsurgical reduction of the labial frenum with and without orthodontic treatment. J Am Dent Assoc, Chicago, v. 42, p. 510-515, 1951.

6. BROADBENT, B. H. Ontogenic development of occlusion. Angle Orthod, Appleton, v. 11, no. 4, p. 223-241, 1941.

7. CEREMELLO, C. P. J. The superior labial frenum and the midline diastema and their relation to growth and development of the oral structures. Am J Orthod, v. 39, p.120-139, 1953.

8. DEWELL, B. F. The normal and the abnormal labial frenum: clinical differentiation. J Am Dent Assoc, Chicago, v. 33, p. 318-329, Mar. 1946.

9. GASS, J. R. et al. Familial correlations and heritability of maxillary midline diastema. Am J Orthod Dentofacial Orthop, St. Louis, v.123, no.1, p. 35-39, Jan. 2003
10. GRABER, T. M. Ortodoncia: teoria y práctica. 3. ed. México, DC: Interamericana, 1980.

11. JANSON, G. et al. Fechamento ortodôntico do diastema entre incisivos centrais superiores durante a dentadura mista: relato de um caso clínico. R Dental Press Ortodon Ortop Facial, Maringá, v. 3, n. 4, p. 73-8, jul./ago. 1998.

12. KELMAN, M. B.; DUARTE, C. A. O freio labial superior e a sua influência na Ortodontia e Periodontia: revisão da literatura. Rev Assoc Paul Cirurg Dent, São Paulo, v. 45, n. 5, p. 581584, set./out. 1991.

13. KEROSUO, $\mathrm{H}$. et al. The influence of incisal malocclusion on the social attractiveness of young adults in Finland. Eur $\mathbf{J}$ Orthod, London, v. 17, p. 505-512, 1995.

14. LAVELLE, C. L. B.; FOSTER, T. D. Crowding and spacing of teeth in an adult british population. Dent Practice, Cincinnati, v.19, no. 7, p. 239-242, Mar. 1969.

15. LAVELLE, C. L. B. The distribution of diastemas in different human population samples. Scand J Dent Res, Copenhagen, v. 78 , p. $530-534,1970$.

16. MONDELLI, J.; PEREIRA, M. A.; MONDELLI, R. F. L. Etiologia e tratamento dos diastemas dentários. Biodonto, Bauru, v. 1, n. 3, p.11-111, maio/jun. 2003.

17. MOSSEY, P. A. The heritability of malocclusion: part 2. the influence of genetic in malocclusion. , London, v. 26, no. 3 , p.195-203, Sept. 1999. 
18. MOYERS, R. E. Ortodontia. 4. ed. Rio de Janeiro: Guanabara Koogan, 1991.

19. NAINAR, S. M. H. Incidence and etiology of midline diastema in a population in south India. Angle Orthod, Appleton, v. 59 no. 4, p. 277-282, 1989

20. OESTERLE, L. J.; SHELLHART, W. C. Maxillary midline diastemas: a look at the causes. J Am Dent Assoc, Chicago, v. 130, no.1, p. 85-94, 1999

21. POPOVICH, F.; THOMPSON, G. W.; MAIN, P. A. The maxillary interincisal diastema and its relationship to the superior labial frenun and intermaxillary suture. Angle Orthod, Appleton, v. 47, no. 4, p. 265-271, Oct. 1977.

22. RAVELI, D. B. et al. Diastema interincisal. Fatores etiológicos: relato de casos clínicos. J Bras Ortodon Ortop Facial, Curitiba, v. 3, n.18, p. 36-42, dez. 1998

23. RICHARDSON, E. R. et al. Biracial study of the maxillary midline diastema. Angle Orthod, Apleton, v. 43, no. 4, p. 438-443, Oct. 1973

24. ROSSATO, C.; MARTINS, D. R. Espaçamento anterior na dentadura decídua e sua relação com o apinhamento na dentadura permanente. Ortodontia, São Paulo, v. 26, n. 2, p. 81-87, maio/ago. 1993.
25. SANIN, C.: SEKIGUCHI, T. SAVARA, B. S. A clinical method for the prediction of closure the central diastema. J Dent Child, Chicago, v. 36, no. 6, p. 415-418, 1969

26. SANTOS-PINTO, A.; PAULIN, R.F.; MARTINS, L. P. Tratamento de diastema entre incisivos centrais superiores com aparelho fixo combinado a aparelho removível: casos clínicos. J Bras Ortodon Ortop Facial, Curitiba, v. 8, n. 44, p.133-140, mar./ abr. 2003.

27. STEIGMAN, S: GERSHKOVITZ, E. HARARI, D Characteristics and stability of spaced dentition. Angle Orthod, Appleton, v. 55, no. 4, p. 321-328, Oct. 1985.

28. STEIGMAN, S.; WEISSBERG, Y. Spaced dentition. An epidemiologic study. Angle Orthod, Appleton, v. 55, no. 2, p.167176, Apr. 1985.

29. SULLIVAN, T. C.; TURPIN, D. L.; ARTUN, J. A postretention study of patients presenting with a maxillary median diastema. Angle Orthod, Appleton, v. 66, no. 2, p.131-138, 1996.

30. TAYLOR, J. E. Clinical observations relating to the normal and abnormal frenum labii superioris. Am J Orthod, St. Louis, p. $646-650,1939$

Endereço para correspondência

Renato Rodrigues de Almeida

Faculdade de Odontologia de Bauru - USP

Alameda Otávio Pinheiro Brisolla 9-75

17012-901 - Bauru - SP

e-mail: renatinhaalmeida@uol.com.br 